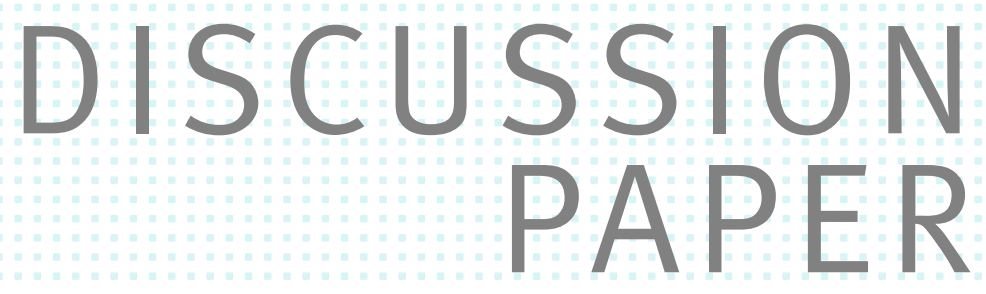

/ / ROBERT GERMESHAUSEN AND KATHRINE VON GRAEVENITZ

State Mandates on Renewable Heating Technologies and the Housing Market 


\title{
State Mandates on Renewable Heating Technologies and the Housing Market
}

\author{
Robert Germeshausen, and Kathrine von Graevenitz ${ }^{\dagger}$
}

July 25, 2019

\begin{abstract}
We study the effect of a state level mandate on renewable heating technologies on the housing market. The mandate requires a minimum share of $10 \%$ renewable energy sources when changing the heating system in the existing building stock. As renewable energy sources are still more expensive than conventional alternatives this mandate could lower the relative price of homes in the existing building stock when a replacement of the heating system is impending. We implement a two stage difference-in-differences nearest neighbor matching approach to identify the effect on prices taking advantage of differences in regulation by location and vintage of the building stock. Our results find no evidence of an effect of the mandate on housing prices.
\end{abstract}

Keywords: Building regulations; Renewable energy sources; Hedonic pricing.

JEL-Classification: Q42, Q48, Q58

${ }^{*}$ ZEW - Leibniz Centre for European Economic Research, P.O. Box 1034 43, 68034 Mannheim, Germany, \& University of Münster, Center of Applied Economics Research Münster (CAWM), Am Stadtgraben 9, 48143 Münster, Germany, Email: Robert.Germeshausen@zew.de.

${ }^{\dagger}$ Corresponding author. ZEW - Leibniz Centre for European Economic Research, P.O. Box 1034 43, 68034 Mannheim, Germany, Email: Kathrine.vonGraevenitz@zew.de. 


\section{Introduction}

Climate change is one of the biggest challenge currently faced by the world's policy makers. It requires massive changes in the way energy is generated and consumed across the board. Several countries have ambitious targets and policies in place to shape the transition towards a low carbon society. The energy transition in Germany is a prime example with its demanding targets for German energy policy. One of the serious challenges in Germany and many other countries concerns residential heating. In Germany residential heating accounts for more than $20 \%$ of final energy consumption and energy used for heating is only weakly linked with power generation (BMWi, 2017). The need for a heating transition in addition to a power transition is apparent. Recent years have seen some progress being made and the current share of renewable energy source in heating is close to the target of $14 \%$ at the federal level. However, renewable energy sources are predominantly used in housing built after 2009 and less so in the older housing stock, which makes up the vast majority of residential homes in Germany. This paper studies the impacts of a state mandate directed at increasing the share of renewable energy sources used in the older building stock on the housing market.

Federal regulation for heating in Germany comes mainly in the form of building codes which apply to new construction, including a federal mandate on renewable heating technologies. Raising the rate at which refurbishments occur and making the existing building stock more energy efficient has long been a priority. The main federal tools are subsidy schemes such as the Market Incentive Program (Marktanreizprogramm) for heating technologies based on renewable energy sources and the subsidized loans offered by the government-owned development bank KfW (Kreditanstalt für Wiederaufbau). In addition to these measures, the federal state of Baden-Wuerttemberg introduced a state law mandating the use of renewable energy sources in the existing building stock when exchanging the heating system. Repeated discussions to extend the state law to cover all of Germany point to the relevance of evaluating the policy. The Baden-Wuerttemberg state mandate on renewable heating technologies increases the costs of retrofitting existing homes by mandating use of renewable heating technologies or the implementation of other compliance options, such as superior insulation to reduce greenhouse gas emissions associated with the existing building stock. ${ }^{1}$ At least two effects on the housing market of introducing such a mandate are conceivable: 1) Retrofitting activity could decline in response to an increase in costs as more homeowners decide to repair an existing heating system rather than replace it. This could in the future lead to a lower quality of the existing housing stock than would otherwise have been the case, and consequently, to lower prices. 2) The expected compliance cost could capitalize into property prices. Such capitalization should reflect the perceived extra cost induced by the mandate and the (subjective) probability of a heating system failure making a retrofitting necessary and

\footnotetext{
${ }^{1}$ Germeshausen et al. (2017) study the effect of the same state mandate on the uptake of renewable heating technologies and find little evidence that homeowners have complied by installing more renewable heating technologies.
} 
provides an indication of the perceived financial burden associated with the mandate. Unfortunately, there is no micro data available on retrofitting activity in Germany and we cannot assess this dimension directly. However, capitalization of retrofitting cost into housing prices for existing homes with pre-installed heating systems can be assessed using available housing market data. We ask the question whether the state mandate had an impact on housing prices of affected homes. We construct a research design based on the spatial discontinuity at the state border as well as the variation in applicability of the mandate by building vintage. Specifically, we estimate a spatial difference-in-differences model comparing the prices of old and new houses for sale within and outside of BadenWuerttemberg. This design allows us to identify effects on the prices of houses for sale in the existing building stock in Baden-Wuerttemberg.

Our findings reveal no evidence of statistically significant capitalization in the housing market. Possible explanations for this result include the availability of relatively low cost measures to comply with the state mandate (such as using bio-oil or bio-gas in conventional fossil fuel heating systems). It may be that the cost of complying using these measures is sufficiently low, that they are dwarfed by other expenditures associated with retrofitting. Alternatively, the salience of the regulation may be low among sellers (or they may perceive it as low among buyers) resulting in a failure to incorporate such capitalization in their asking prices.

The remainder of the paper is organized as follows. Section 2 provides a short review of the related literature and Section 3 describes the background on building and renewable heating regulation in Germany. Section 4 presents the underlying data. Section 5 explains our empirical strategy. The results are shown in Section 6 . Section 7 discusses our findings, and Section 8 concludes.

\section{Related literature}

Our paper contributes to the growing literature addressing rationality of homeowners and saliency of energy costs related to space heating. Past research has found that energy costs are salient to home buyers. For example, several studies from a variety of countries show that homes with energy labels certifying them as relatively efficient sell at a price premium (see e.g. Eichholtz et al., 2010; Brounen and Kok, 2011; Hyland et al., 2013). Myers (forthcoming) uses variation in fuel prices in Massachusetts, USA, to investigate their impact on the housing market. She finds that effects on house (transaction) prices are consistent with full capitalisation of future energy cost.

For Germany, evidence has been found that mandatory disclosure of energy use information in the shape of energy performance certificates reduces asking prices of the relatively energy inefficient houses. The study by Frondel et al. (2018) focuses on the period 2013 to 2015 and examines the introduction of mandatory energy performance certificates in May 2014. They hypothesize that particularly sellers of less efficient houses would be reluctant to reveal accurate information on energy performance in the absence 
of mandatory disclosure. Their findings support this hypothesis. The introduction of mandatory energy performance disclosure causes asking prices to decline by up to $11 \%$ for those sellers who would not otherwise have disclosed energy performance information. Distinguishing between building vintage, the effect is found to be insignificant for houses built in 2002 or later and increase with age for houses built prior to that (almost $4 \%$ for homes built between 1977 and 2002 and almost $10 \%$ for homes built prior to 1977).

Our study is also relevant to the emerging literature on the effect of building energy codes on energy consumption and home values. Bruegge et al. (2019) study the effectiveness and distributional impacts of building energy standards in California, USA. By exploiting spatial and temporal variation in the stringency of California's building energy standards they identify the effectiveness of building energy codes in reducing energy use and the effects of varying levels of stringency on the prices and characteristics of homes. They find that stricter energy codes reduce the size and the number of bedrooms primarily in homes occupied by low-income households by $4-6 \%$. They also find that building code stringency capitalises into housing prices and increases dispersion across income quintiles. For low-income households, stricter energy building codes lower prices by some $8-12 \%$ whereas for higher income households prices increase by $2 \%$ on average. The authors conclude that these effects on prices are inadequately explained by the changes in observable housing characteristics which suggests that unobservable characteristics change as well in response to the stringency of the building energy codes.

In contrast to existing studies, our paper addresses the effect of a mandate on technology choice when retrofitting existing homes. Almost all building energy codes focus only on construction of new homes neglecting the vast majority of houses in the existing housing stock. Our research design is similar to that of Bruegge et al. (2019), but in contrast to their study, the main characteristics of the houses subjected to the mandate on renewable heating are fixed and cannot be adjusted in response. Germeshausen et al. (2017) study the effect of the same state mandate on the uptake of renewable heating technologies. They find no evidence that the state mandate has induced additional uptake of renewable heating technologies such as solar thermal collectors or biomass furnaces. However, alternative compliance measures involving insulation or the use of bio-oil or bio-gas also come with additional costs in comparison to the status quo and may capitalize into housing prices.

\section{Background}

\subsection{Building energy codes in Germany}

Germany has had building energy codes regulating the thermal insulation of buildings since 1977 and energy efficiency requirements on newly installed and existing heating systems since 1978. Amendments have increased the stringency of these requirements at regular intervals. The Energy Savings Ordinance (Energieeinsparverordnung, EnEv) introduced in 2002, regulates the annual primary energy requirement of newly con- 
structed and renovated buildings. The energy performance standards in the Energy Savings Ordinance have since become increasingly stringent in a series of amendments. Approximately two thirds of the residential buildings in Germany were built prior to 1979 according to ARGE (2016). However, energy retrofitting has been carried out for the large majority of these homes. Popular energy efficiency measures include improved efficiency of heating systems, as well as window and to a lesser degree roof insulation. Our empirical strategy focuses on comparing homes for sale in Baden-Wuerttemberg to those in the three neighboring states: Hesse, Bavaria and the Rheinland-Palatinate. There is some variation in energy efficiency of housing across states. In 2012 the energy use intensity for a single or two-family house in Baden-Wuerttemberg was 161.7 kilowatt hour (kWh) per square meter ( $\mathrm{sqm}$ ) in comparison to $180.6 \mathrm{kWh}$ per sqm in Hesse, 157.2 $\mathrm{kWh}$ per sqm in Bavaria and $170.6 \mathrm{kWh}$ per sqm in the Rhineland-Palatinate (Walberg, 2012).

\subsection{Renewable energy in space heating}

The German Renewable Energies Heat Act (EEWaermeG) is a federal law mandating a minimum share of renewable energy sources for all new buildings with a building permit granted after 1 January 2009 when it entered into force. The federal law aims to increase the share of renewable energy sources in heating to $14 \%$ by 2020 . It mandates a minimum share of renewable energy use in space heating. The exact share depends on the technology employed (e.g. $15 \%$ for solar thermal collectors, $50 \%$ for biomass or a heat pump, and $30 \%$ for bio-gas). Alternative measures of compliance include exceeding the energy efficiency requirements in the Energy Savings Ordinance to degrees specified in the law.

The federal law on renewable energy sources in space heating partly replaces a BadenWuerttemberg specific law introduced in 2008. In contrast to the federal law however, the state mandate addresses both new and existing buildings. The Baden-Wuerttemberg state mandate $(E$ Waerme $G$ ) requires a minimum share of renewable energy use in space heating of at least $10 \%$ when replacing the heating system in the existing building stock for residential use. It exists only in the state of Baden-Wuerttemberg where it was introduced in 2008 with effect from 2010 for existing homes. Compensating measures are similar to those allowed in the federal law for new buildings. The state mandate was amended in 2015 with stricter requirements (now $15 \%$ ) but more lenient compliance measures (e.g. producing a refurbishment plan is equivalent to $5 \%$ renewables in energy use regardless whether the identified measures in this plan are implemented). There is a fine for non-compliance of up to 100,000 Euro. The law is enforced by the local building authorities at the municipal level.

Renewable heating technologies are generally more expensive than conventional heating with the cheapest option on the market in the period being natural gas. The net present value (NPV) of the difference in costs amounts to between 9,000 and 11,000 Euro 
when comparing natural gas and the cheapest renewable technology. ${ }^{2}$ This calculation assumes a life time of 18 years for an installation and a discount rate of $4.5 \%$. Other compliance options such as e.g. facade insulation are much more expensive. The cheapest alternative by far is to use conventional fuels with a minimum share of bio-oil (NPV cost difference between 3,000 and 13,000 Euro over 18 years) or bio-gas (NPV cost difference of 2,000 to 5,000 Euro over 18 years) assuming the old heating system is replaced with a newer system with the same fuel type. ${ }^{3}$ While only about $31 \%$ of buildings used for housing in Baden-Wuerttemberg heat with gas according to BDEW (2015b), changing the heating system from oil to gas would involve additional one-time costs of between 3,000 and 8,000 Euro. The 2018 evaluation of the state mandate commissioned by the Ministry of the Environment, Climate Protection and the Energy Sector Baden-Wuerttemberg (Pehnt et al., 2018) considers the compliance methods chosen as reported by the local building authorities: In 2010, renewable energy technologies (solar thermal collectors, biomass or heat pumps) were used in approximately $52 \%$ of the cases with solar thermal installations accounting for roughly $30 \%$ of the cases alone. Heating with bio-oil or bio-gas was used in $23 \%$ of the cases, and alternative measures (e.g. insulation) were used in $16 \%$ of the cases. However, the use of bio-oil and bio-gas has been increasing over time. In 2015 prior to the amendment taking effect, compliance through bio-oil or bio-gas accounted for $46 \%$ of the cases and the share for renewable energy technologies dropped to $34 \%$, with alternative measures at $12 \%$. Over the whole period the share of cases exempt from the mandate due to infeasibility remains stable at 8-9 \%. The state mandate has also been accused of causing a decline in the state's rate of refurbishment. Although micro data to study this potential effect is not available (UM, 2011), Germeshausen et al. (2017) investigate aggregate data and find suggestive evidence that the replacement rate of heating systems in Baden-Wuerttemberg is lower than expected after the introduction of the mandate.

As the state mandate comes into effect when a heating system is replaced an impact on housing prices would depend on the (discounted) extra cost of complying with the mandate as well as the perceived likelihood of having to replace the heating system within the ownership period. There are subsidy schemes at the federal level for investments in residential space heating. The investment cost subsidies for renewable heating technologies from the Market Incentive Program (Marktanreizprogramm) vary by technology and mostly lie in the region 9-11 \% of the investment cost. The effect of the Baden-Wuerttemberg state mandate on uptake of this subsidy scheme is studied in Germeshausen et al. (2017). The German KfW(Kreditanstalt für Wiederaufbau) also provides investment cost subsidies and subsidized loans for retrofitting of existing homes (e.g. "Energieeffizient Sanieren" product numbers 151 and 430). These cover between

\footnotetext{
${ }^{2}$ We have calculated these values using data described in Germeshausen et al. (2017).

${ }^{3}$ These costs are estimated as in Germeshausen et al. (2017) based on the heating energy demand for an example house described in the evaluations of the subsidy scheme for renewable heating technologies. We use 2019 information on the price of bio-oil and biogas both of which were approximately $10 \%$ more expensive than conventional oil and gas.
} 
10 and $30 \%$ of the investment cost though maximum 30,000 Euro per unit of housing, but come with strict minimum requirements on the level of energy efficiency attained.

\section{Data}

The state-specific regulation and the regional nature of housing markets make an empirical strategy based on comparing housing prices along the state border a natural choice. We make use of several data sets for the analysis. The primary data set is the data on housing prices provided by Empirica GmbH. This data consists of characteristics and asking prices for individual homes offered for sale through real estate websites. We merge the housing market data with data on regional socio-economic indicators from the INKAR data set and data on the real estate tax factor determining the municipal property tax supplied by the German Federal Statistical Office (Destatis). The summary statistics of the data set are shown in table 1 and table 2 .

\subsection{Housing market data}

Micro data on actual transactions in the housing market is considered to be the gold standard for hedonic research. However, such information is not available at a large scale for Germany. Instead we use data on asking prices scraped from online real estate portals and provided to us by Empirica GmbH. This data is available from 2012 onwards and covers all of Germany. As the state mandate for existing buildings was introduced in 2010 this implies that our sample does not cover the period before and after it became effective. Instead of comparing sales prices across time we therefore develop an identification strategy based on location inside or outside the regulated state of BadenWuerttemberg and building vintage as described further below. Our strategy has the advantage that it does not require the housing market or in particular the hedonic function to be stable over time. In contrast to many other developed economies, Germany has experienced a real estate boom starting in 2009, which makes the assumption of a stable hedonic function over this period less likely to hold.

We have obtained data for the state of Baden-Wuerttemberg and the neighboring states Hesse, Rheinland-Palatinate and Bavaria. Our sample covers houses in counties (Landkreise) on both sides of the Baden-Wuerttemberg state border as shown in figure 1. For the period from 2012 to 2014 we have a total of 56,678 houses offered for sale. We reduce the data set by removing observations with missing information on important characteristics as well as houses built before 1901, listed properties, or houses without central heating. In addition we exclude houses posted online for more than a year, houses with renewable heating systems that were built before 2009, and houses that are connected to district heating. ${ }^{4}$ Furthermore, we remove observations with outlier

\footnotetext{
${ }^{4}$ We keep new homes with renewable heating in place in the sample. The share of renewables in this building segment is high due to the federal building codes on renewable heating in new homes (EEWaermeG). In our sample, renewable technologies are installed in about $60 \%$ of the new buildings.
} 
values (defined as observations that lie outside of the upper quartile by more than 1.5 times the interquartile range) on living space and number of rooms as well as the lower and upper $0.5 \%$ of the price offers. After data cleaning we are left with 32,586 unique houses in the data set. The data includes a wide variety of characteristics such as size, number of rooms, year of construction, main source of heating, quality of the house as graded by Empirica GmbH and availability of a garden, etc. There is also information on whether or not the house was refurbished after 2008 when the state mandate was passed. However, we have no information about what the refurbishment consisted of and whether the heating system was exchanged. We include the variable to control for the fact that a change of heating system may have taken place for these houses and treat them as a separate category. We thus have three classes of buildings: old (constructed before 2009), new (built 2009 and later) and those refurbished after 2008. While the data set does contain information on the location of the house offered for sale, this information is generally limited to the centroid of the municipality or postal code area in question.

Figure 1: Counties on both sides of the border of Baden-Wuerttemberg

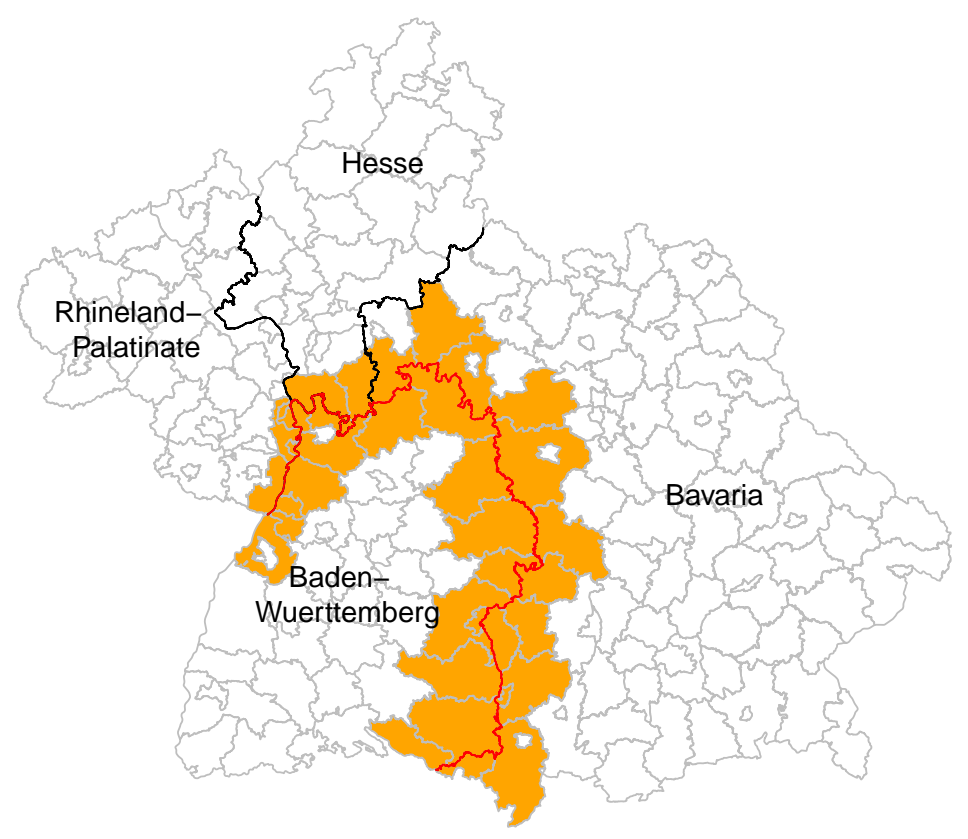

Notes: The figure displays the counties on both sides of the red border of Baden-Wuerttemberg (bottom left) and its neighbors (from the top left) Rheinland-Palatinate, Hesse and Bavaria for which housing offers were collected. 


\subsection{INKAR and Destatis}

The INKAR data is provided by the German Federal Institute for Research on Building, Urban Affairs and Spatial Development and available for download from www.inkar.de (Indicators and maps of spatial and urban development). This data set consists of time series on a wide variety of indicators, e.g. unemployment, tax revenues, age distribution of the population, type of housing, etc. We use the most disaggregated level of information available, which is at the level of the 4,567 municipalities or municipal associations (Gemeindeverbände). The real estate tax factor (Hebesatz) is set at the municipal level and determines the level of property tax paid by the owner together with the assessed value of the plot (Einheitswert) and the type and value of construction (Grundsteuermesszahl). The tax factor varies substantially across municipalities as can be seen in table 1. Income tax revenues relate to the share of income taxes appropriated to the municipality, which is currently $12 \%$ on capital income and $15 \%$ for other forms of income.

\begin{tabular}{lccccc}
\hline Variable & Min & Median & Mean & Max & N \\
\hline Price [EUR] & 53,200 & 259,300 & 276,484 & 855,880 & 32,586 \\
Space [sqm] & 30 & 145 & 154 & 287 & 32,586 \\
Year of construction & 1901 & 1980 & 1980 & 2016 & 32,586 \\
No. of rooms & 1.00 & 5.00 & 5.66 & 10.00 & 32,586 \\
Unemployment [\%] & 0.90 & 2.90 & 3.08 & 7.20 & 32,586 \\
Income Tax Revenues [EUR per capita] & 243 & 440 & 440 & 636 & 32,586 \\
Real Estate Tax Factor [\%] & 150 & 350 & 352 & 800 & 32,586 \\
\hline
\end{tabular}

Table 1: Summary statistics: Numeric variables

Notes: The table shows the summary statistics for the numeric variables in our data set covering the period from 2012 to 2014 . We excluded dwellings built prior to 1901 or listed homes as well as homes with missing information on main characteristics. We also excluded homes posted for more than 12 months online. Furthermore, we dropped houses with renewable heating systems that were built before 2009 or that are connected to district heating. Finally we remove outlier values on living space and number of rooms as well as the lower and upper $0.5 \%$ of the price offers. 


\begin{tabular}{lrrlcr}
\hline Variable & Mean & \multicolumn{1}{c}{ N } & Variable & Mean & \multicolumn{1}{c}{$\mathrm{N}$} \\
\hline Semi-detached house & 0.173 & 5,643 & Bad building condition & 0.088 & 2,854 \\
1-family house & 0.519 & 16,909 & Building projected (No) & 0.844 & 27,516 \\
Unsp. 1- or 2-family house & 0.060 & 1,947 & Building projected (Yes) & 0.156 & 5,070 \\
Row house & 0.122 & 3,962 & Border Hesse & 0.177 & 5,774 \\
2-family house & 0.127 & 4,125 & Border Rhineland-Palatinate & 0.320 & 10,418 \\
Garden (No) & 0.370 & 12,066 & Border Bavaria & 0.503 & 16,394 \\
Garden (Yes) & 0.630 & 20,520 & Outside Baden-Wuerttemberg & 0.447 & 14,564 \\
Simple equipment & 0.043 & 1,387 & Baden-Wuerttemberg & 0.553 & 18,022 \\
Good equipment & 0.398 & 12,953 & Not OLD & 0.229 & 7,471 \\
High quality equipment & 0.269 & 8,759 & OLD & 0.771 & 25,115 \\
Normal equipment & 0.291 & 9,487 & No refurbishment after 2008 & 0.936 & 30,499 \\
Good building condition & 0.451 & 14,701 & Refurbishment after 2008 & 0.064 & 2,087 \\
Normal building condition & 0.461 & 15,031 & & & \\
\hline
\end{tabular}

Table 2: Summary statistics: Categorical variables

Notes: The table shows the summary statistics for the categorical variables in our data set covering the period from 2012 to 2014 . We excluded dwellings built prior to 1901 or listed homes as well as homes with missing information on main characteristics. We also excluded homes posted for more than 12 months online. Furthermore, we dropped houses with renewable heating systems that were built before 2009 or that are connected to district heating. Finally we remove outlier values on living space and number of rooms as well as the lower and upper $0.5 \%$ of the price offers.

\section{Empirical strategy: Difference-in-Differences Nearest Neighbor Matching}

We utilize differences in the coverage of the state mandate to identify the potential effect on housing prices adapting an approach developed in Haninger et al. (2017) in the context of brownfield remediation. In particular, homes constructed after 1 January 2009, in all German states were subject to the federal Renewable Energies Heat Act requiring a minimum use of renewable heating technologies. In contrast, only in the state of Baden-Wuerttemberg are homes built before that date subject to a state mandate on renewable heating in existing buildings. We identify an effect on housing prices by analyzing differences in housing prices across the state border between new and existing buildings.

We write the hedonic price function to explain prices $P_{i t k}$ as a function of the home's covariates $X_{i t k}$ where indexes refer to: $i$ (house), $t$ (year) and $k$ (border segment defined by neighboring state). Some of the homes are built before $2009\left(O L D_{i k}=1\right)$ and some are built after $\left(O L D_{i k}=0\right)$. Furthermore, we have a third category, namely homes built before 2009, but which underwent a refurbishment after 2008 (Refurbishment(> $2008)_{i k}=1$ ). Similarly, some homes are located in the state of Baden-Wuerttemberg $\left(B W_{i k}=1\right)$ and some are located outside $\left(B W_{i k}=0\right)$. We model the house characteristics, including refurbishment status, using a flexible function $f\left(X_{i t k} ; \theta_{t}\right)$. For those 
homes, that are built before 2009 and located in Baden-Wuerttemberg we expect to find an average treatment effect on the treated (ATT), $\pi_{t}$, of the state mandate if one exists:

$$
P_{i t k}=\beta_{0 t}+\beta_{1 t} O L D_{i k}+\beta_{2 t} B W_{i k}+\pi_{t} O L D_{i k} \times B W_{i k}+f\left(X_{i t k} ; \theta_{t}\right)+u_{i t k} .
$$

A goal of this estimation procedure is to cancel out the effect of the flexible function of a home's characteristics so that this function does not have to be estimated. The procedure is based on (bias-corrected) matching and requires two steps:

In the first step consider all homes built before $2009\left(O L D_{i k}=1\right)$, which include also homes that were refurbished after 2008:

$$
P_{i t k}=\left(\beta_{0 t}+\beta_{1 t}\right)+\left(\beta_{2 t}+\pi_{t}\right) B W_{i k}+f\left(X_{i t k} ; \theta_{t}\right)+u_{i t k}
$$

Each home in Baden-Wuerttemberg $\left(B W_{i k}=1\right)$ is matched to a set of $J$ control homes in the neighboring state using genetic matching (cf. Diamond and Sekhon, 2013). For each of the treatment homes, a counterfactual is constructed based on the matched controls (i.e. a weighted average of the price of each of the $J$ control homes, $P_{j}^{(i t k)}$ ). Based on the counterfactual, an individual treatment effect for each treatment home can be calculated and stored in the vector $P_{t}^{O L D}$ of length $N_{t}$ corresponding to the number of old homes in Baden-Wuerttemberg in year $t$. The average treatment effect for all old homes is given by:

$$
\left(\beta_{2 t}+\pi_{t}\right)=\frac{1}{N_{t}} \sum_{i=1}^{N_{t}}\left(P_{i t k}-\frac{1}{J} \sum_{j=1}^{J} P_{j}^{(i t k)}\right) .
$$

Now consider all homes built after $2009\left(O L D_{i k}=0\right)$ :

$$
P_{i t k}=\beta_{0 t}+\beta_{2 t} B W_{i k}+f\left(X_{i t k} ; \theta_{t}\right)+u_{i t k} .
$$

Following the same procedure described above with matching each of the homes in Baden-Wuerttemberg to a new home outside delivers a set of individual treatment effects stored in the vector $P_{t}^{N E W}$ of length $\tilde{N}_{t}$ and an average treatment effect:

$$
\beta_{2 t}=\frac{1}{\tilde{N}_{t}} \sum_{i=1}^{\tilde{N}_{t}}\left(\tilde{P}_{i t k}-\frac{1}{J} \sum_{j=1}^{J} \tilde{P}_{j}^{(i t k)}\right) .
$$

We need to further correct for potential bias in the first-stage estimates. This is particularly important given that our treated and control homes are always located in different municipalities, i.e. we need to correct for characteristics of these municipalities that differ such as the real estate tax factor, etc. As in Haninger et al. (2017) we apply the bias-corrected matching estimator from Abadie and Imbens (2011). The details on the implementation of this approach are found in Appendix A.1.

In the second step the ATT for each year is recovered by simply differencing the average treatments from the first step:

$$
\pi_{t}=\frac{1}{N_{t}} \sum_{i=1}^{N_{t}}\left(P_{i t k}-\frac{1}{J} \sum_{j=1}^{J} P_{j}^{(i t k)}\right)-\frac{1}{\tilde{N}_{t}} \sum_{i=1}^{\tilde{N}_{t}}\left(\tilde{P}_{i t k}-\frac{1}{J} \sum_{j=1}^{J} \tilde{P}_{j}^{(i t k)}\right),
$$


where the first and the second term correspond to the average treatment effect for old homes, $P_{i t}^{O L D, b c m}$, and for new homes, $P_{i t}^{N E W, b c m}$, respectively. In other words, it is a bias-corrected Difference-in-Differences estimator utilizing variation across the state borders and home vintages. The difference between the prices of new homes in BadenWuerttemberg and neighboring states should capture state specific factors such as e.g. the property transfer tax which differ between states and are likely to capitalize into prices. The difference between the prices of old homes in Baden-Wuerttemberg and the neighboring states should capture these factors as well as the effect of the state mandate on renewable heating. Therefore differencing the two differences isolates the effect of the renewable heating mandate.

The bias-corrected Difference-in-Differences estimator does not directly account for differences in the individual house vintages. In particular, it does not easily allow us to control for refurbishment status after the state mandate was introduced. To this purpose we also estimate a simple linear model where we regress the bias-corrected estimates $P_{t}^{b c m}$ on an indicator for construction prior to 2009, matching covariates including refurbishment status and control for municipality fixed effects $\left(\nu_{r}\right)$ :

$$
P_{t}^{b c m}=\pi_{t} O L D_{i}+X_{i t k} \delta_{t}+\nu_{r}+\epsilon_{i t k}
$$

As a final robustness check, we also estimate a standard cross-sectional hedonic regression with spatial fixed effects in which we specifically model $f\left(X_{i t k} ; \theta_{t}\right)$ from equation 1.

Our research design is potentially vulnerable to spillover effects: As demand for older homes affected by the mandate declines along the border within Baden-Wuerttemberg demand for substitutes in the neighboring states could increase. This would lead us to overstate the average impact on prices in comparison to capitalization for homes further from the border where substitutes are not available. Our estimates may therefore be seen as an upper bound on the capitalization of the private cost of the mandate.

\section{$6 \quad$ Results}

In this section we first describe briefly the procedure used to match houses on either side of the Baden-Wuerttemberg border. We then describe in detail our findings based on the two difference-in-differences approaches described above. The robustness check using a more standard hedonic framework is found in the appendix.

\subsection{Matching}

To control for differences in observable characteristics we use the method of genetic matching as developed by Diamond and Sekhon (2013) and match on several housing characteristics: garden availability, quality indicators (condition, furnishing class), number of rooms, living space and year of construction. At the municipal level we include information on unemployment, income tax revenues and the real estate tax factor. We 
match exactly on housing type (detached house, row house, etc.) as well as the federal border segment to ensure spatial proximity of treatment and control houses. We also match exactly with regard to homes undergoing refurbishment after 2008 and, for new buildings, whether they are projected. Finally, the propensity score estimated based on the same variables is included in the algorithm. The genetic matching algorithm comprises both Mahalanobis matching and propensity score matching and the weights determine the extent to which each approach influences the outcome. We match houses within and outside of Baden-Wuerttemberg for each calendar year separately. We match with replacement each treated house with two control houses $(J=2)$. QQ-plots from our matching procedure can be found in the appendix. They show that matching improves the balance in covariates significantly across the board.

2012

\begin{tabular}{|c|c|c|c|c|c|}
\hline & Old - BW & New - BW & Total BW & Old - Non BW & New - Non BW \\
\hline All & 4,717 & 1,443 & 6,160 & 3,976 & 1,154 \\
\hline Matched & 4,705 & 1,437 & 6,142 & 2,523 & 696 \\
\hline Unmatched & 12 & 6 & 18 & 1,453 & 458 \\
\hline \multicolumn{6}{|c|}{2013} \\
\hline & Old - BW & New - BW & Total BW & Old - Non BW & New - Non BW \\
\hline All & 4,487 & 1,323 & 5,810 & 3,492 & 1,042 \\
\hline Matched & 4,483 & 1,314 & 5,797 & 2,260 & 659 \\
\hline Unmatched & 4 & 9 & 13 & 1,232 & 383 \\
\hline \multicolumn{6}{|c|}{2014} \\
\hline & Old - BW & New - BW & Total BW & Old - Non BW & New - Non BW \\
\hline All & 4,629 & 1,423 & 6,052 & 3,814 & 1,086 \\
\hline Matched & 4,620 & 1,410 & 6,030 & 2,763 & 663 \\
\hline Unmatched & 9 & 13 & 22 & 1,051 & 423 \\
\hline
\end{tabular}

Table 3: Genetic matching: Overview by year of sale

Notes: The table shows the number of observations by category (new/old) and location within or outside BadenWuerttemberg in the full and matched samples, as well as the number of observations not matched.

The number of observations in the full and matched samples is shown in table 3 and the spatial distribution in figure 2. Old houses (incl. refurbished) are red or blue depending on their location within and outside Baden-Wuerttemberg, whereas new homes are orange or green. The matched sample is distributed along both sides of the state border without any obvious gaps or clusterings. 
Figure 2: Matched sample, old and new houses on both sides of the border

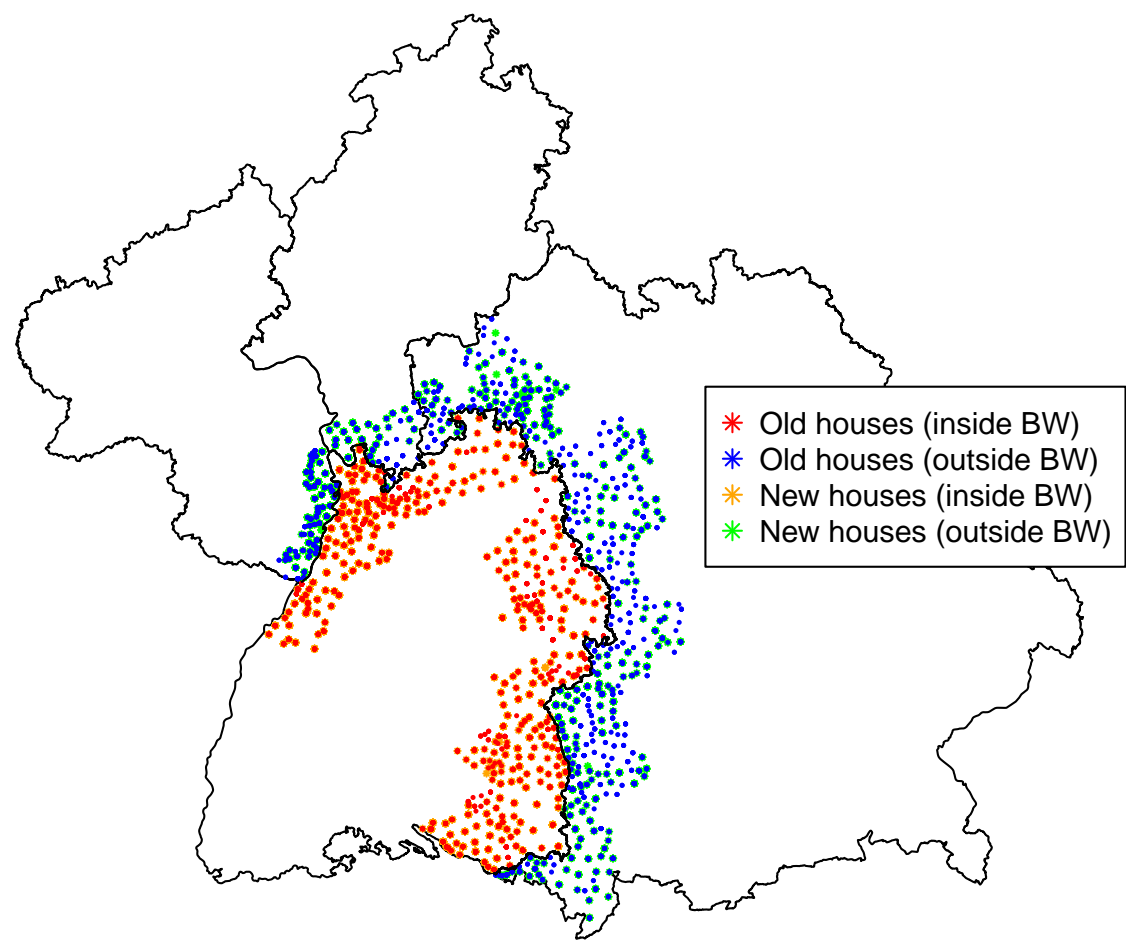

Notes: The figure displays the matched sample of houses. Points showing old houses are red/blue while new houses are orange/green depending on location inside or outside Baden-Wuerttemberg (BW). A point corresponds to the centroid of the municipality in which the house is located.

\subsection{Capitalization of the state mandate into prices}

The main findings from the estimations of equation 5 and equation 6 are displayed in table 4 in panels a) and b) respectively. Panel a) shows the differences in means between the price differences of old and new buildings (equation 5). In panel b), we regress the price differences that we obtained in the first step on an indicator for old homes, the matching covariates, and include municipality fixed effects (equation 6).

We find no significant effect of the mandate in the first specification based on the means of the bias-adjusted estimates as well as in the second panel with the regression corrected results. Furthermore, we fail to reject that the coefficients for old buildings are equal to the ones for buildings that underwent a refurbishment after 2008. 


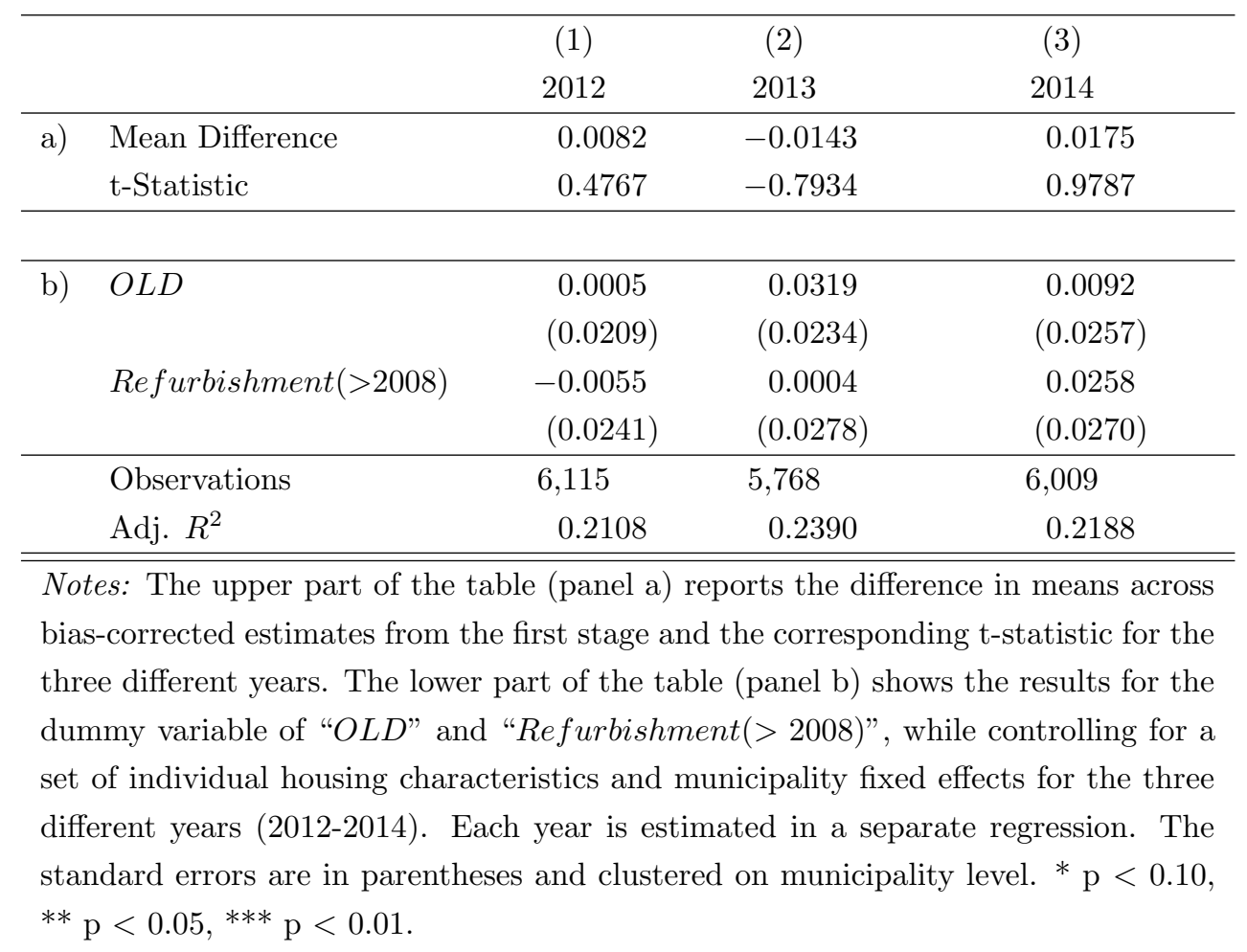

Table 4: Results: DD-NNM

\section{Discussion}

What factors may explain the fact that we find no significant evidence of capitalization of the state mandate in the housing market? The fact that we base our analysis on asking prices may raise the question whether sellers are responsive to concerns regarding energy costs. Given the scarcity of transactions data for Germany, Frondel et al. (2018) also use asking prices for their study of the impact of mandatory disclosure of energy performance for housing. For a subsample of observations in Berlin, they are able to obtain transaction prices as well and compare list and transaction prices. They find a small but relatively constant difference between the two over time. The introduction of mandatory energy performance certificates does not seem to affect this gap. While this result may be specific to the Berlin subsample for which both types of data were available, it does provide us with some confidence that our findings are relevant to the realized prices in the housing market as well. Moreover, the fact that Frondel et al. (2018) do find effects on the asking prices suggests that sellers are aware of the saliency of a house's energy performance for buyers. Their study focuses on the period 2013-2015 which overlaps with our time frame.

Given that sellers are indeed responsive to energy costs, why do we find little evidence of capitalization? One explanation may be that the state mandate is not wellknown among sellers. Whereas buyers have a strong incentive to investigate potential retrofitting costs, the same may not hold for sellers. They may be less aware of current 
legal requirements as a result. Alternatively, it may be that the pending revision of the 2008 state mandate led to uncertainty about the stringency of the mandate in the future. While the final revision increases the share of renewable energy from 10 to $15 \%$, it also introduces several additional compliance measures some of which are very low cost. An official paper revealed several elements of the revision in 2013 with resulting critical news paper coverage including headlines such as "The intention alone counts" (Die Absicht alleine zählt, Zeitung für den Energiemarkt, 2013). The expectation that the revised mandate may be more lenient could have reduced pressure on sellers to lower their asking price.

The rising share of the use of bio-gas and bio-oil for compliance with the mandate may also explain why we find no significant evidence of capitalization. One of the effects of the state mandate has likely been to increase the supply of bio-gas on offer from gas providers in Baden-Wuerttemberg: Bernauer and Reisch (2018) study the structure of tariffs offered for gas across Germany in 2017 and find that whereas at a national level $20 \%$ of gas suppliers offer a bio-gas tariff, almost half of these suppliers were located in Baden-Wuerttemberg with the remaining companies spread equally among the other 15 German states. In fact they found that $97 \%$ of the gas companies in Baden-Wuerttemberg offered a bio-gas product. While they have no historical data it seems likely that this supply effect may be associated with the state mandate.

Finally, our analysis only recovers the immediate effect on asking prices. If the mandate indeed causes a reduction in retrofitting activities in the state of BadenWuerttemberg, it could be that over time the quality of the housing stock declines, which in itself could cause lower prices. Such an effect would likely take several years to manifest itself however, and we would not identify it within the period covered by the present analysis.

\section{Conclusion}

In this paper we study the effect of a state mandate on renewable energy for heating on the housing market. We construct a research design based on the spatial discontinuity at the state border and taking advantage of the variation in applicability of the mandate by building vintage. Specifically, we estimate a spatial difference-in-differences model comparing the prices of old and new houses for sale within and outside of BadenWuerttemberg. This design allows us to identify effects on the asking prices of houses for sale in the existing building stock in Baden-Wuerttemberg.

We find no significant evidence of capitalization of the mandate into asking prices in the housing market. We speculate that our finding may be due to a) low salience of the mandate among sellers, b) the expected revision of the state law, which happened in 2015 and introduced more flexibility and additional compliance measures of lower costs, and c) the increased availability of low cost compliance measures in the shape of bio-gas and bio-oil. If the latter explanation is true, our findings suggest that the 
financial burden associated with the mandate is small. On the other hand, if retrofitting activity in Baden-Wuerttemberg has declined in consequence of the state mandate a cost in terms of declining quality of the housing stock may emerge over time.

\section{Acknowledgements}

We would like to thank Nicolai Kuminoff and Ulrich Wagner for helpful comments and suggestions. This work also benefits from discussions at the 2019 Conference of the European Association of Environmental and Resource Economists as well as from seminars at ZEW Mannheim and University of Münster. We thank Empirica GmbH for providing us with housing market data. Furthermore, we thank Michael Detzel for excellent research assistance. Financial support by the German Federal Ministry of Education and Research (FKZ 03SFK4Z0) and by the ZEW - Leibniz Centre for European Economic Research is gratefully acknowledged. 


\section{References}

Abadie, A., And G. W. Imbens (2011): "Bias-Corrected Matching Estimators for Average Treatment Effects," Journal of Business 86 Economic Statistics, 29(1), 1-11.

ARGE (2016): "Wohngebäude - Fakten 2016," Mitteilungsblatt, 253.

BDEW (2015): "Wie heizt Deutschland?," https://www.bdew.de/media/documents/ BDEW-Broschuere-Wie-heizt-Deutschland-2015.pdf, extracted on March 20, 2019.

Bernauer, Manuela AND Reisch, Lucia (2018): "Grüne Defaults als Instrument einer nachhaltigen Energienachfragepolitik ," https://researchapi.cbs.dk/ws/portalfiles/portal/56139845/Bernauer_Reisch_Gr_ne_Defaults_als_

Instrument_einer_nachhaltigen_Energienachfragepolitik.pdf, extracted on March 21, 2019 .

BMWI (2017): "Energieeffizienz in Zahlen," https://www.bmwi.de/Redaktion/DE/ Publikationen/Energie/energieeffizienz-in-zahlen.pdf, extracted on August 8, 2017.

Brounen, D., And N. KoK (2011): "On the economics of energy labels in the housing market," Journal of Environmental Economics and Management, 62(2), 166-179.

Bruegge, C. D., T. Deryugina, and E. Myers (forthcoming): "The Distributional Effects of Building Energy Codes," Journal of the Association of Environmental and Resource Economists.

Diamond, A., And J. S. Sekhon (2013): "Genetic Matching for Estimating Causal Effects: A General Multivariate Matching Method for Achieving Balance in Observational Studies," Review of Economics and Statistics, 95(3), 932-945.

Eichholtz, P., N. KoK, and J. M. Quigley (2010): "Doing Well by Doing Good? Green Office Buildings," American Economic Review, 100(5), 2492-2509.

Frondel, M., A. Gerster, and C. Vance (2018): "The Power of Mandatory Quality Disclosure: Evidence from the German Housing Market," Working Paper.

Germeshausen, R., K. von Graevenitz, and M. Achtnicht (2017): "Does the Stick make the Carrot more Attractive? State Mandates and Uptake of Renewable Heating Technologies," ZEW Working Paper.

Haninger, K., L. Ma, and C. Timmins (2017): "The Value of Brownfield Remediation," Journal of the Association of Environmental and Resource Economists, 4(1), $197-241$.

Hyland, M., R. C. Lyons, and S. Lyons (2013): "The value of domestic building energy efficiency - evidence from Ireland," Energy Economics, 40, 943 - 952. 
Ministry of the Environment, Climate Protection and the Energy Sector BADEN-WÜRTTEMBERG (2011): "Erfahrungsbericht zum Erneuerbare-Wärme-Gesetz Baden-Wuerttemberg," Ministerium für Umwelt, Klima und Energiewirtschaft (UM) Baden-Württemberg.

Myers, E. (forthcoming): "Are Home-Buyers Myopic? Evidence from Capitalization of Energy Costs," American Economic Journal: Economic Policy.

Pehnt, M., U. Weiss, S. Fritz, D. Jessing, J. Lempik, P. Mellwig, M. Nast, V. Bürger, T. Kenkmann, J. Zieger, J. Steinbach, and K. Lambrecht (2018): "Evaluation des Erneuerbare-Wärme-Gesetz (EWärmeG)," Final Report on behalf of the Ministry of the Environment, Climate Protection, and the Energy Sector BadenWürttemberg.

WAlBerG, D. (2012): "Typische Energieverbrauchskennwerte deutscher Wohngebaude," Presentation at the workshop Die energetische Zukunft des Wohngebaudebestands in Darmstadt, Germany, 31.05.2012 .

Zeitung FÜr DEN EnergiemarkT (2013): "Schon die Absicht zählt," Zeitung für den Energiemarkt, 17 July 2013. 


\section{A Appendix}

\section{A.1 Bias-correction}

We apply the bias-corrected matching estimator from Abadie and Imbens (2011). To this purpose we define the conditional expected price of a home in Baden-Wuerttemberg given its attributes had it been located in the neighboring state instead as $\mu_{0}\left(X_{i t k}\right)$ :

$$
\mu_{0}\left(X_{i t k}\right)=E\left[P_{i t k}^{0} \mid X_{i t k}\right]
$$

The conditional expected price is approximated using a linear model:

$$
\hat{\mu}_{0}\left(X_{j t k}\right)=X_{j t k} \hat{\theta}_{w=0},
$$

where $\theta_{w=0}$ is estimated using weighted OLS based on the all control homes in the matched sample and the weight is given by the frequency with which the home is used as a match. With the estimated $\hat{\theta}_{w=0}$ in hand, the conditionally expected price of homes within Baden-Wuerttemberg is predicted:

$$
\hat{\mu}_{0}\left(X_{i t k}\right)=X_{i t k} \hat{\theta}_{w=0} .
$$

The bias-adjusted matching estimator $\left(\hat{P}^{(i t k)}\right)$ amends the simple matching estimator $P^{(i t k)}$ by including the correction terms above:

$$
P_{i, t}^{O L D, b c m}=P_{i t k}-\frac{1}{J} \sum_{j=1}^{J} \hat{P}_{j}^{(i t k)}
$$

replacing $\hat{P}^{(i t k)}$ by its parts:

$$
P_{i, t}^{O L D, b c m}=P_{i t k}-\left(\frac{1}{J} \sum_{j=1}^{J} P_{j}^{(i t k)}+\hat{\mu}_{0}\left(X_{i t k}\right)-\hat{\mu}_{0}\left(X_{j t k}\right)\right) .
$$

A similar procedure is used to recover bias-corrected estimates of the treatment effect for new homes, $P_{i, t}^{N E W, b c m}$. All estimates are then stacked into the vector $P_{t}^{b c m}$ of length $N_{t}+\tilde{N}_{t}$.

\section{A.2 Genetic matching}

To control for differences in observable characteristics we use the method of genetic matching as developed by Diamond and Sekhon (2013). It is a form of nearest neighbor Mahalanobis distance matching with replacement and weighting of the individual variables:

$$
G M D\left(X_{i}, X_{j}, W\right)=\sqrt{\left.\left(X_{i}-X_{j}\right)^{T}\left(S^{-1 / 2}\right)^{T} W S^{-1 / 2}\left(X_{i}-X_{j}\right)\right)} .
$$

The weights $W$ of covariates $X$ are determined by minimizing a loss function to achieve covariate balance. Our loss function is defined as the largest individual discrepancy 
based on p-values from a Kolmogorov-Smirnov test for differences in distributions and paired t-tests for each variable.

In addition to QQ-plots, we compute standardized mean differences, i.e. the difference from treated and untreated houses divided by the standard deviation of the treated houses, on all matching variables, which can be found in the appendix. Matching reduces these differences for almost all variables in all years and for new and old houses. Although this result becomes evident from the alignment in distributions between treated and control houses as shown by the QQ-plots, the mean values may provide a quick assessment of the improvements. Furthermore, the standardized mean differences illustrate that characteristics in the sample may vary over year, underlining the importance to analyze the years separately.

The summary statistics for the matched sample pooled across all three years are shown in tables 5 and 6 . The sample characteristics are very similar for the matched sample compared to the full sample characteristics shown above.

\begin{tabular}{lccccc}
\hline Variable & Min & Median & Mean & Max & N \\
\hline Price [EUR] & 53,200 & 265,000 & 281,144 & 855,880 & 27,533 \\
Space [sqm] & 30 & 146 & 155 & 287 & 27,533 \\
Year of construction & 1901 & 1980 & 1981 & 2016 & 27,533 \\
No. of rooms & 1.00 & 5.50 & 5.71 & 10.00 & 27,533 \\
Unemployment [\%] & 1.00 & 2.80 & 2.97 & 7.20 & 27,533 \\
Income Tax Revenues [EUR per capita] & 260 & 447 & 447 & 636 & 27,533 \\
Real Estate Tax Factor [\%] & 200 & 350 & 353 & 800 & 27,533 \\
\hline
\end{tabular}

Table 5: Genetic matching: Summary statistics: Numeric variables

Notes: The table shows the summary statistics for the numerical variables describing the matched sample when pooled for all three years. A comparison to table 1 reveals only very minor changes in the sample summary statistics. 


\begin{tabular}{lcccr}
\hline Variable & Mean & \multicolumn{1}{c}{ N Variable } & Mean & \multicolumn{1}{c}{$\mathrm{N}$} \\
\hline Semi-detached house & 0.183 & 5,039 Bad building condition & 0.085 & 2,347 \\
1-family house & 0.499 & 13,733 Building projected (No) & 0.849 & 23,387 \\
Unsp. 1- or 2-family house & 0.061 & 1,688 Building projected (Yes) & 0.151 & 4,146 \\
Row house & 0.126 & 3,467 Border Hesse & 0.165 & 4549 \\
2-family house & 0.131 & 3,606 Border Rhineland-Palatinate & 0.325 & 8,945 \\
Garden (No) & 0.368 & 10,126 Border Bavaria & 0.510 & 14,039 \\
Garden (Yes) & 0.632 & 17,407 Outside BW & 0.347 & 9,564 \\
Simple equipment & 0.040 & 1,094 BW & 0.653 & 17,969 \\
Good equipment & 0.397 & 10,937 Not OLD & 0.224 & 6,179 \\
High quality equipment & 0.268 & 7,383 OLD & 0.776 & 21,354 \\
Normal equipment & 0.295 & 8,119 No refurbishment after 2008 & 0.936 & 25,774 \\
Good building condition & 0.444 & 12,236 Refurbishment after 2008 & 0.064 & 1,759 \\
Normal building condition & 0.470 & 12,950 & & \\
\hline
\end{tabular}

Table 6: Genetic matching: Summary statistics: Categorical variables

Notes: The table shows the summary statistics for the categorical variables describing the matched sample when pooled over all three years. A comparison to table 2 reveals only very minor changes in the sample summary statistics. 


\section{A.3 QQ-plots: New houses}

Figure 3: QQ-Plots: Treatment and control new houses in all four states: 2012
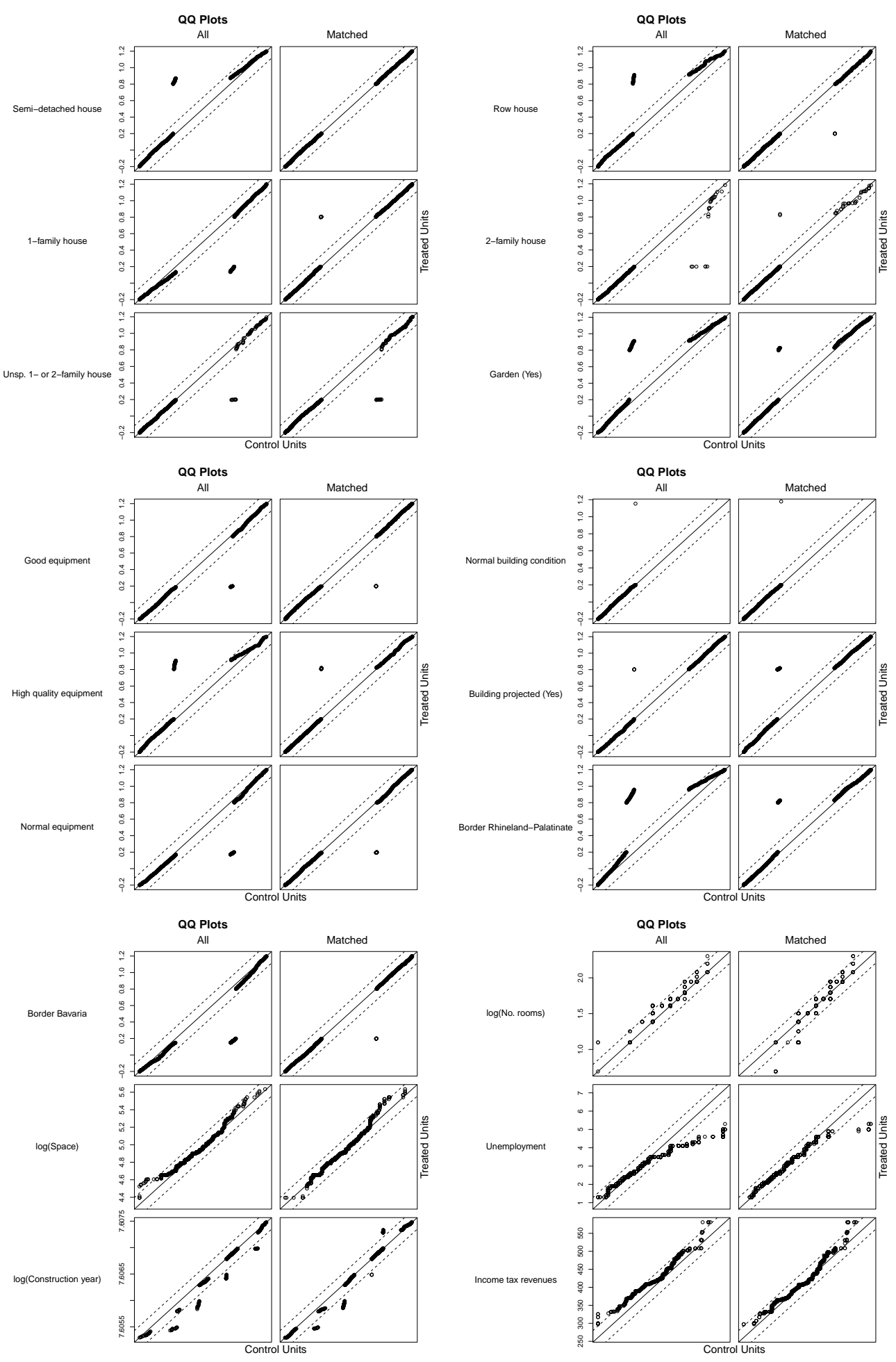


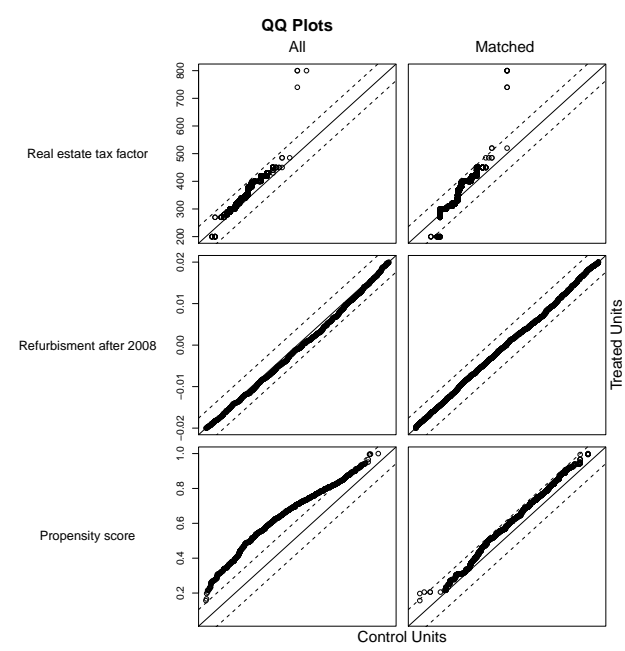

Notes: Based on own computations. The figure shows the quantile-quantile (QQ) plots for the different matching variables in the original and matched sample for new houses in the four states (Baden-Wuerttemberg, Rhineland Palatinate, Hesse and Bavaria) for the year 2012. 
Figure 4: QQ-Plots: Treatment and control new houses in all four states: 2013
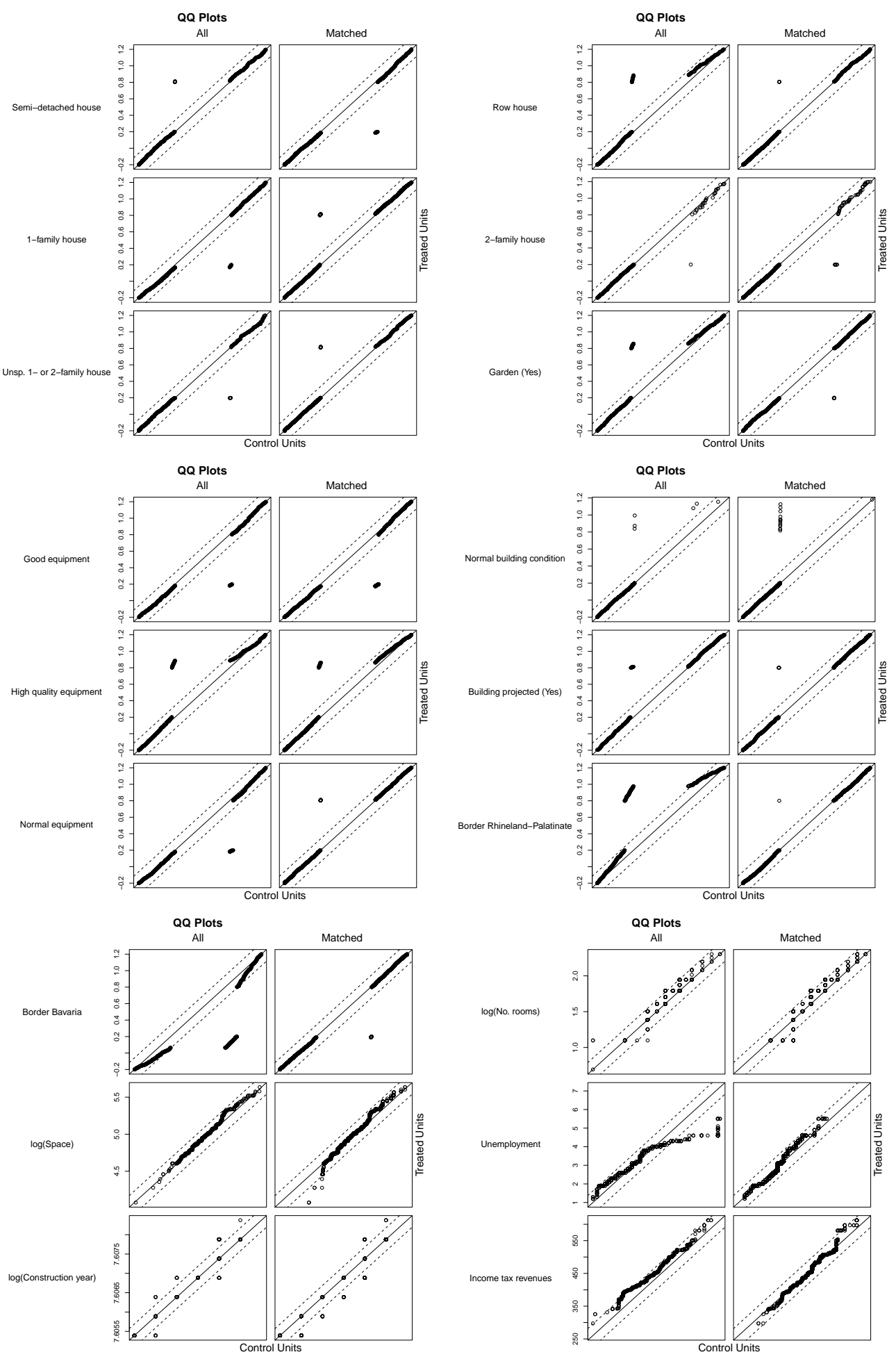


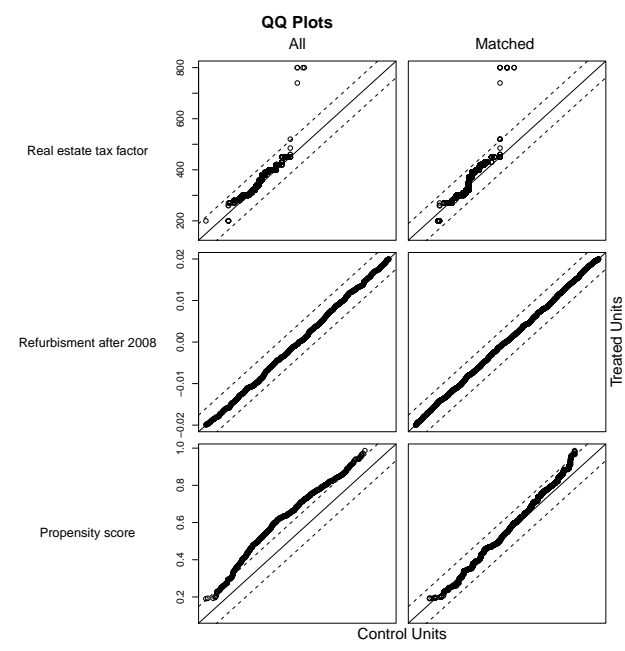

Notes: Based on own computations. The figure shows the quantile-quantile (QQ) plots for the different matching variables in the original and matched sample for new houses in the four states (Baden-Wuerttemberg, Rhineland Palatinate, Hesse and Bavaria) for the year 2013. 
Figure 5: QQ-Plots: Treatment and control new houses in all four states: 2014
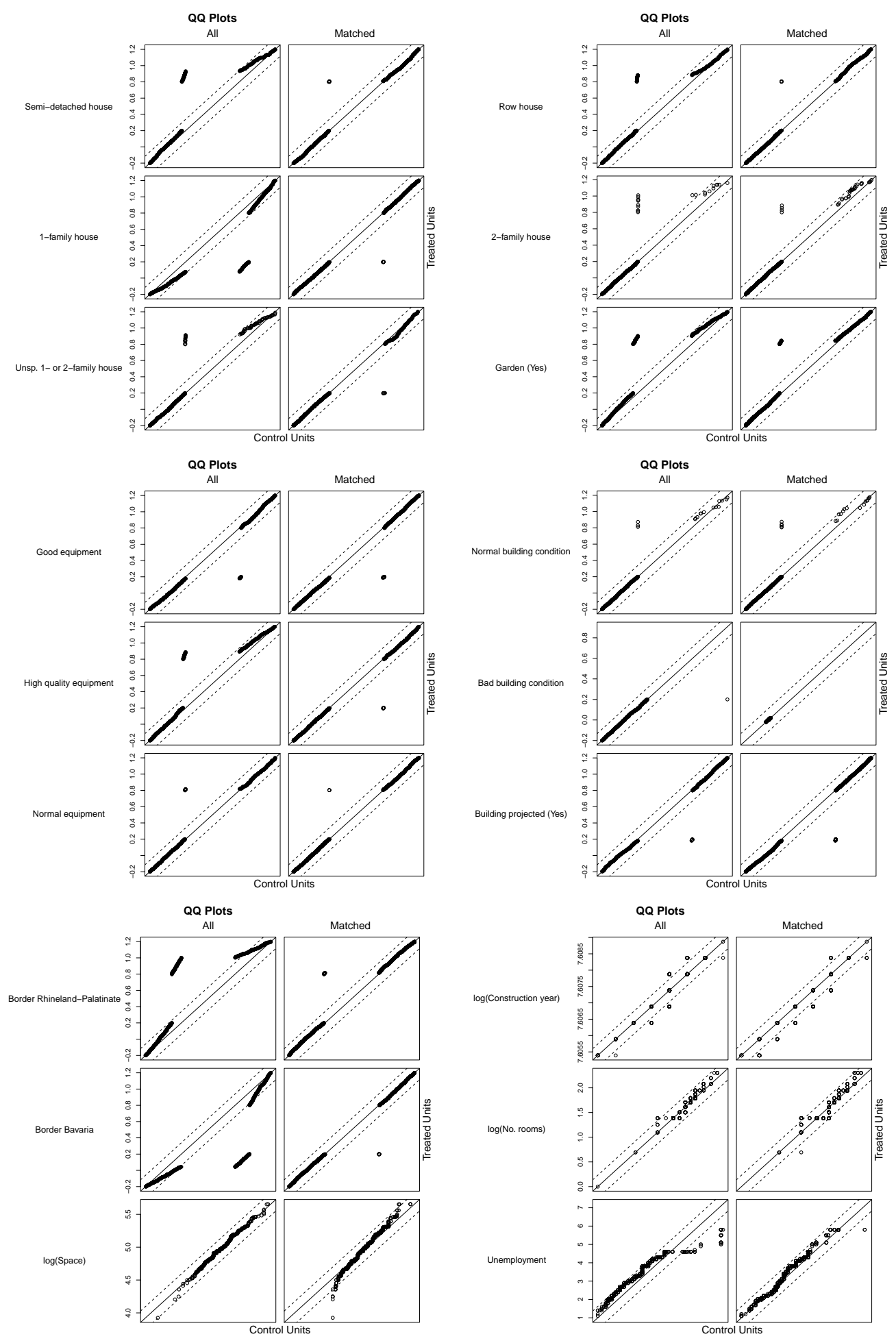


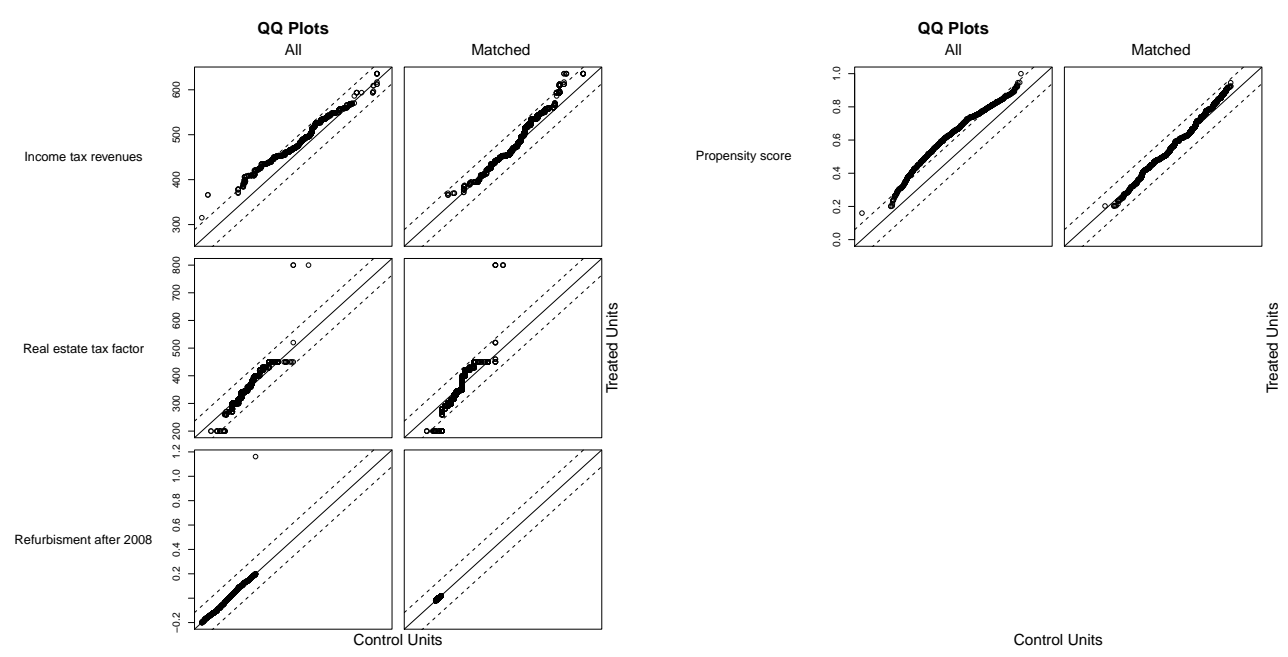

Notes: Based on own computations. The figure shows the quantile-quantile (QQ) plots for the different matching variables in the original and matched sample for new houses in the four states (Baden-Wuerttemberg, Rhineland Palatinate, Hesse and Bavaria) for the year 2014. 


\section{A.4 QQ-plots: Old houses}

Figure 6: QQ-Plots: Treatment and control old houses in all four states: 2012
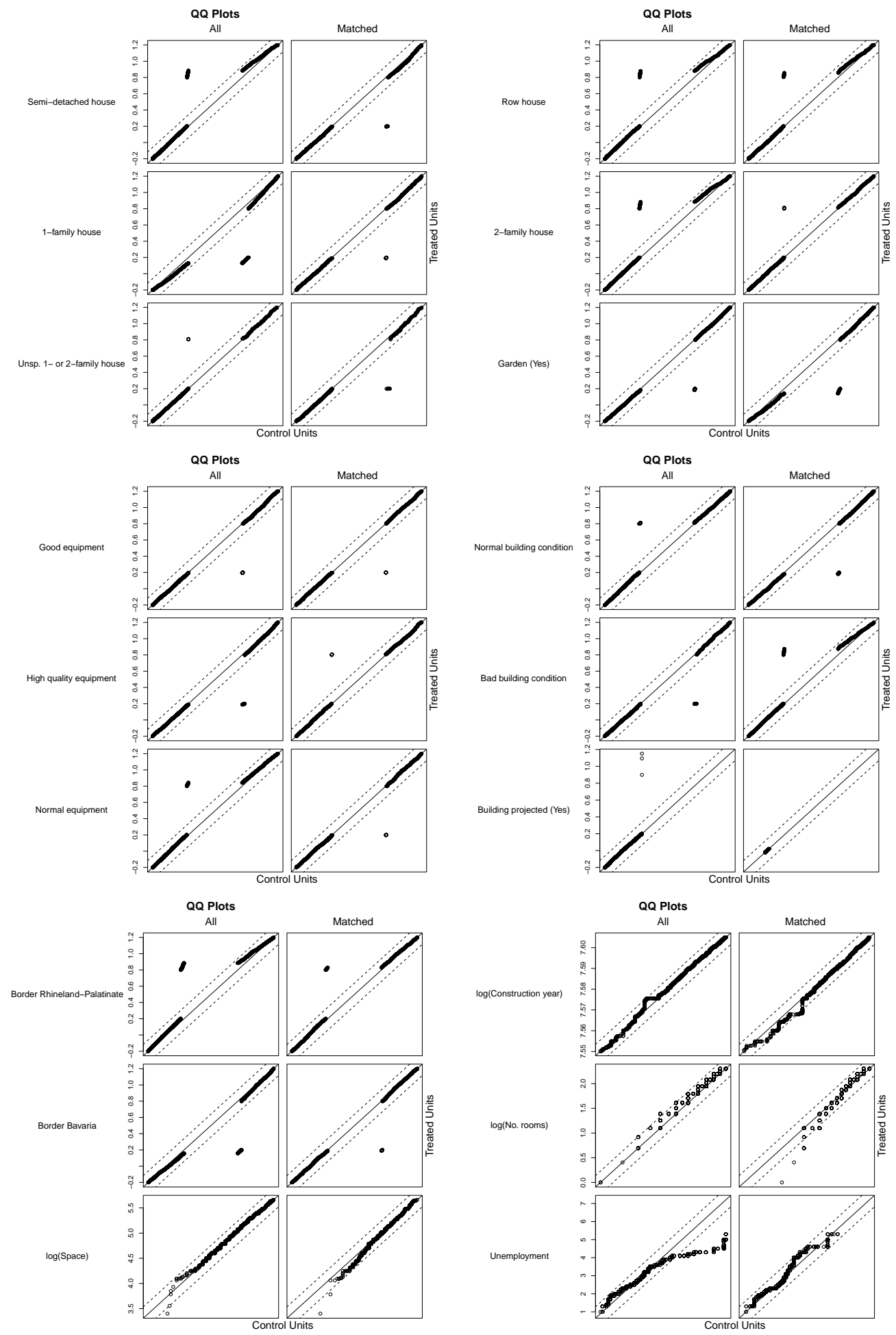

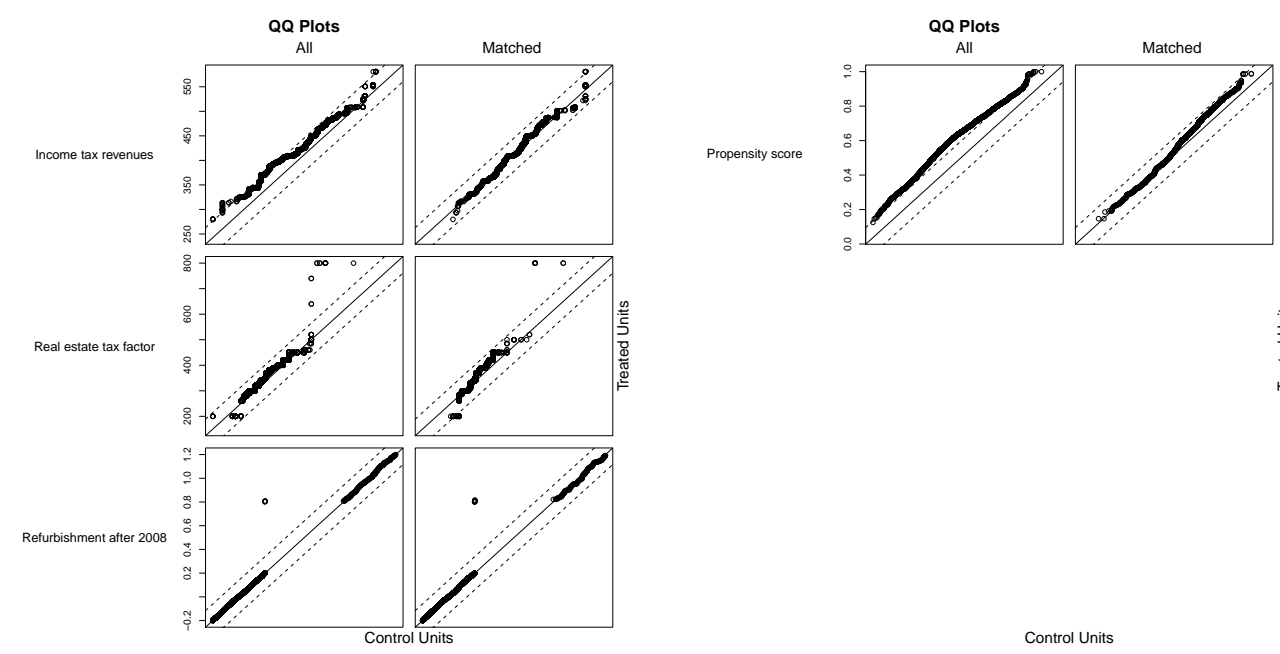

Notes: Based on own computations. The figure shows the quantile-quantile (QQ) plots for the different matching variables in the original and matched sample for old houses in the four states (Baden-Wuerttemberg, Rhineland Palatinate, Hesse and Bavaria) for the year 2012. 
Figure 7: QQ-Plots: Treatment and control old houses in all four states: 2013
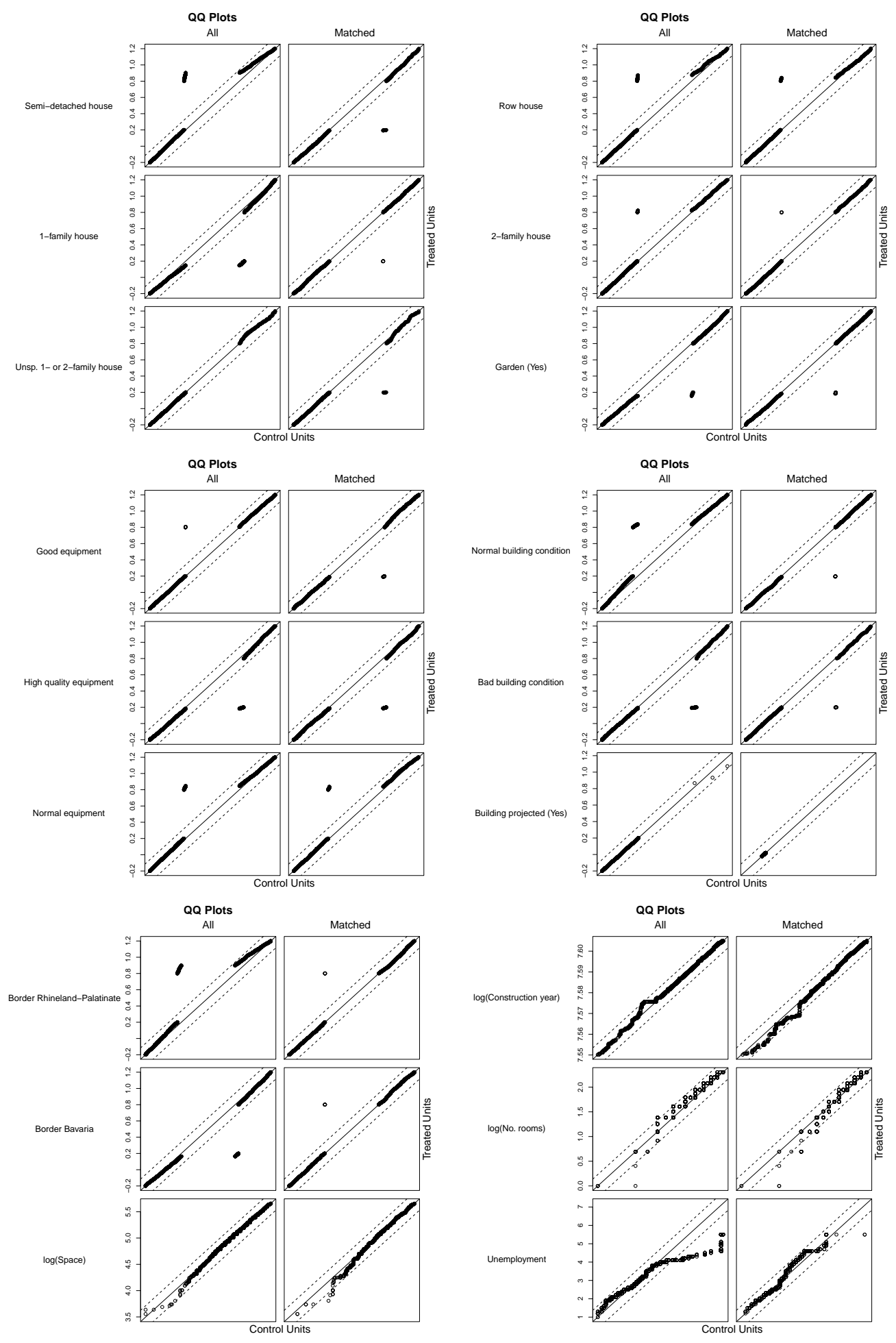

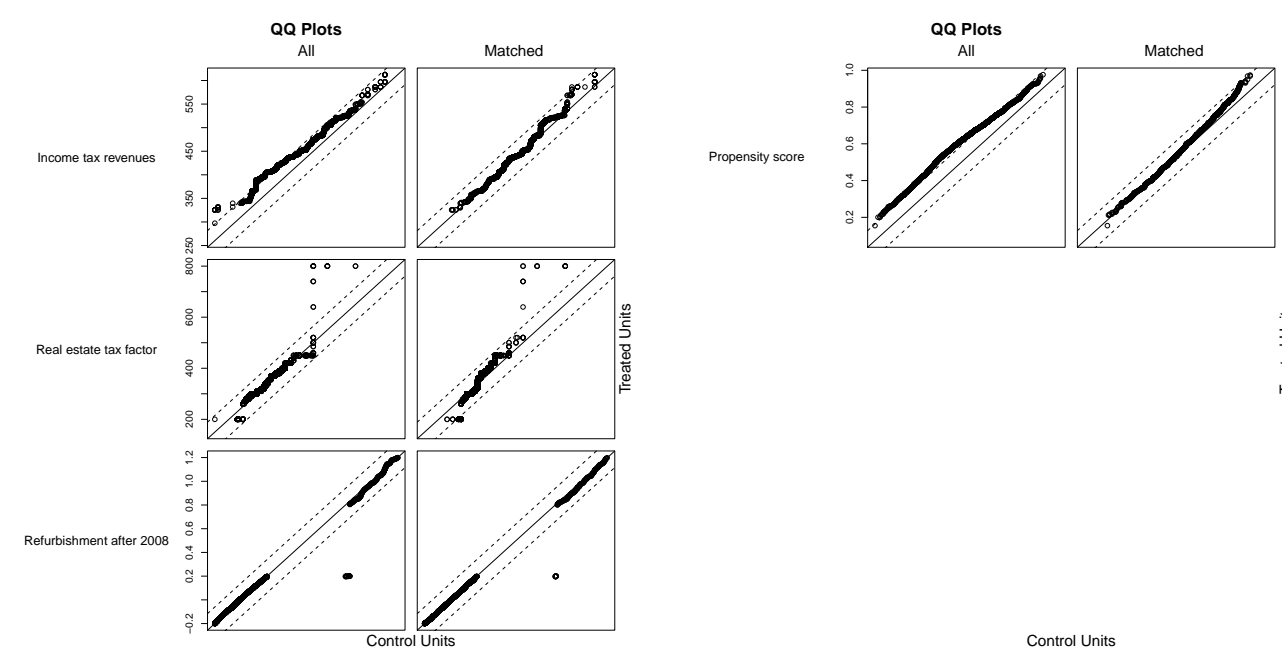

Notes: Based on own computations. The figure shows the quantile-quantile (QQ) plots for the different matching variables in the original and matched sample for old houses in the four states (Baden-Wuerttemberg, Rhineland Palatinate, Hesse and Bavaria) for the year 2013. 
Figure 8: QQ-Plots: Treatment and control old houses in all four states: 2014
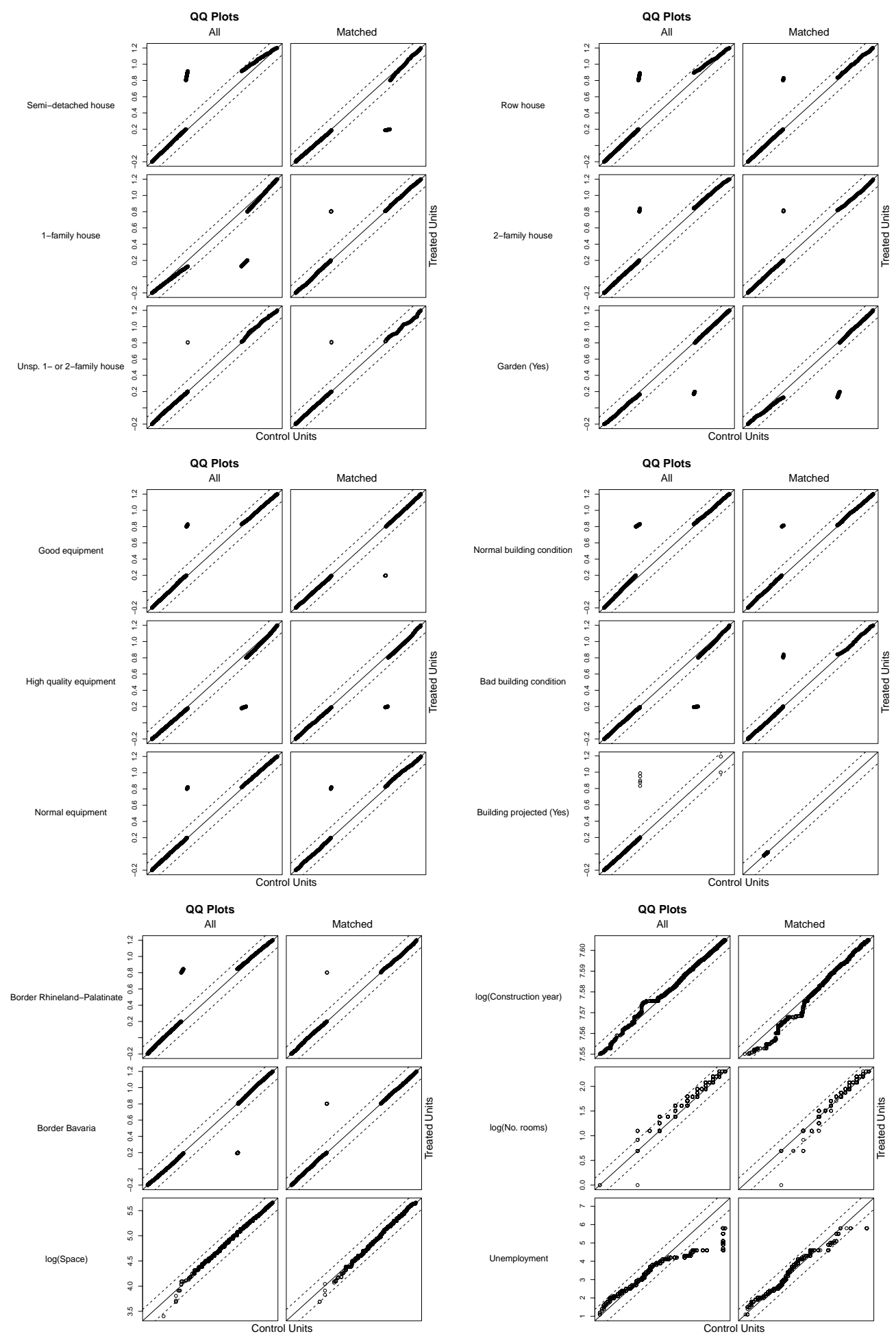

Notes: Based on own computations. The figure shows the quantile-quantile (QQ) plots for the different matching variables in the original and matched sample for old houses in the four states (Baden-Wuerttemberg, Rhineland Palatinate, Hesse and Bavaria) for the year 2014. 

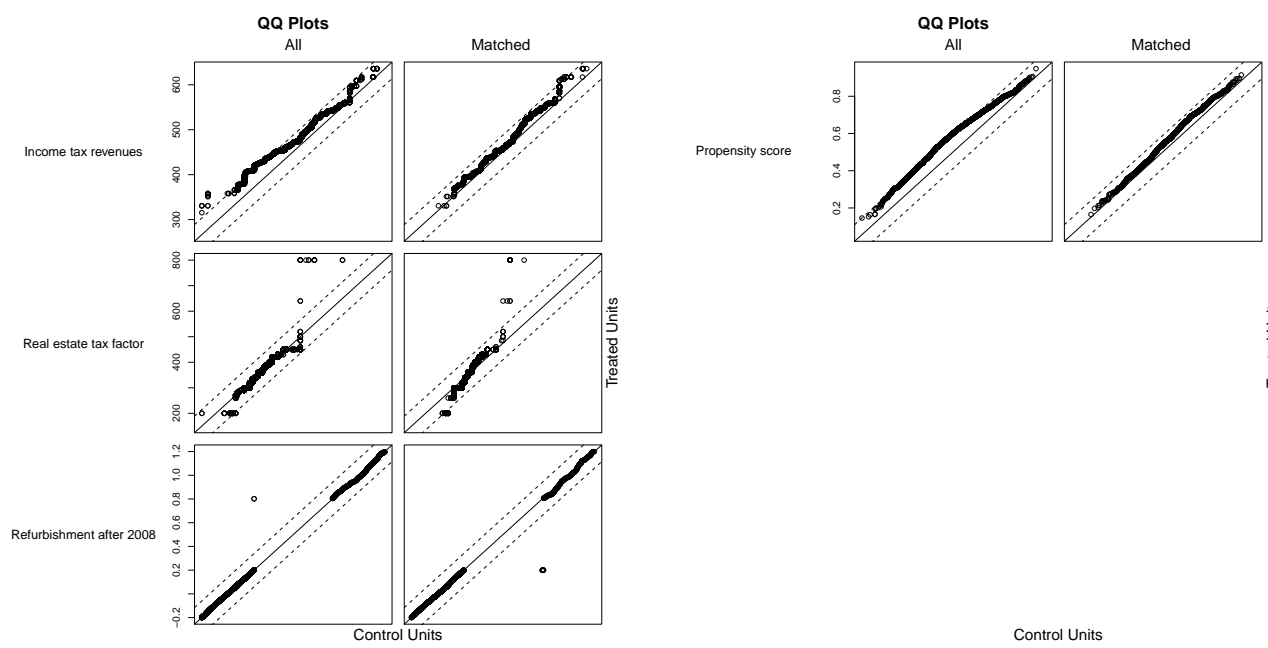

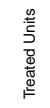

Control Units

Notes: Based on own computations. The figure shows the quantile-quantile (QQ) plots for the different matching variables in the original and matched sample for old houses in the four states (Baden-Wuerttemberg, Rhineland Palatinate, Hesse and Bavaria) for the year 2014.

\section{A.5 Standardized mean differences: New houses}

\begin{tabular}{lrr}
\hline Variable & \multicolumn{1}{c}{ All } & Matched \\
\hline Semi-detached house & 0.1148 & 0.0000 \\
1-family house & -0.1466 & 0.0000 \\
Unsp. 1- or 2-family house & -0.0470 & 0.0000 \\
Row house & 0.1066 & 0.0000 \\
2-family house & -0.0382 & 0.0000 \\
Garden (Yes) & 0.2059 & 0.0130 \\
Good equipment & -0.0370 & -0.0194 \\
High quality equipment & 0.1301 & 0.0069 \\
Normal equipment & -0.0896 & 0.0105 \\
Normal building condition & 0.0263 & 0.0264 \\
Building projected (Yes) & 0.0117 & 0.0000 \\
\hline
\end{tabular}

\begin{tabular}{lrr}
\hline Variable & \multicolumn{1}{c}{ All } & Matched \\
\hline Border Rhineland-Palatinate & 0.3293 & 0.0000 \\
Border Bavaria & -0.1544 & 0.0000 \\
$\log$ (Space) & 0.1070 & 0.0746 \\
$\log$ (Construction year) & -0.1165 & -0.0437 \\
$\log$ (No. rooms) & 0.1698 & 0.0251 \\
Unemployment & -0.2778 & -0.0223 \\
Income tax revenues & 0.4265 & 0.1191 \\
Real estate tax factor & 0.3944 & 0.2371 \\
Refurbisment after 2008 & $\mathrm{NaN}$ & $\mathrm{NaN}$ \\
Propensity score & 1.0181 & 0.3108 \\
& & \\
\hline
\end{tabular}

Table 7: Standardized mean differences for new houses - 2012

Notes: The table shows the standardized mean differences for the full and matched sample for new houses in the year 2012 . 


\begin{tabular}{|c|c|c|c|c|c|}
\hline Variable & All & Matched & Variable & All & Matched \\
\hline Semi-detached house & 0.0162 & 0.0000 & Border Rhineland-Palatinate & 0.3840 & 0.0000 \\
\hline 1-family house & -0.0604 & 0.0000 & Border Bavaria & -0.3944 & 0.0000 \\
\hline Unsp. 1- or 2-family house & -0.0172 & 0.0000 & $\log ($ Space $)$ & 0.1662 & 0.0762 \\
\hline Row house & 0.0849 & 0.0000 & $\log ($ Construction year $)$ & 0.0382 & -0.0343 \\
\hline 2-family house & -0.0013 & 0.0000 & $\log ($ No. rooms $)$ & 0.1356 & 0.0962 \\
\hline Garden (Yes) & 0.0950 & -0.0289 & Unemployment & 0.0211 & 0.0405 \\
\hline Good equipment & -0.0569 & -0.0653 & Income tax revenues & 0.4999 & 0.0023 \\
\hline High quality equipment & 0.1448 & 0.0539 & Real estate tax factor & 0.2071 & 0.1944 \\
\hline Normal equipment & -0.0703 & 0.0236 & Refurbisment after 2008 & $\mathrm{NaN}$ & $\mathrm{NaN}$ \\
\hline Normal building condition & 0.0408 & 0.0638 & Propensity score & 0.7990 & 0.1257 \\
\hline Building projected (Yes) & 0.0584 & 0.0000 & & & \\
\hline
\end{tabular}

Table 8: Standardized mean differences for new houses - 2013

Notes: The table shows the standardized mean differences for the full and matched sample for new houses in the year 2013

\begin{tabular}{lrr}
\hline Variable & \multicolumn{1}{c}{ All } & Matched \\
\hline Semi-detached house & 0.2157 & 0.0000 \\
1-family house & -0.3082 & 0.0000 \\
Unsp. 1- or 2-family house & 0.0722 & 0.0000 \\
Row house & 0.0769 & 0.0000 \\
2-family house & 0.0687 & 0.0000 \\
Garden (Yes) & 0.1938 & 0.0394 \\
Good equipment & -0.0510 & 0.0048 \\
High quality equipment & 0.1379 & -0.0286 \\
Normal equipment & 0.0247 & -0.0016 \\
Normal building condition & 0.0231 & 0.0676 \\
Bad building condition & $\mathrm{NaN}$ & $\mathrm{NaN}$ \\
Building projected (Yes) & -0.0294 & 0.0000 \\
\hline
\end{tabular}

\begin{tabular}{lrr}
\hline Variable & \multicolumn{1}{c}{ All } & Matched \\
\hline Border Rhineland-Palatinate & 0.421 & 0.0000 \\
Border Bavaria & -0.5319 & 0.0000 \\
$\log$ (Space) & 0.0512 & 0.0501 \\
$\log$ (Construction year) & 0.0557 & -0.0294 \\
$\log$ (No. rooms) & 0.0551 & 0.0184 \\
Unemployment & 0.3303 & 0.0956 \\
Income tax revenues & 0.4928 & 0.1206 \\
Real estate tax factor & 0.0549 & -0.0046 \\
Refurbisment after 2008 & 0.0375 & 0.0000 \\
Propensity score & 0.7958 & 0.0645 \\
& & \\
& & \\
\hline
\end{tabular}

Table 9: Standardized mean differences for new houses - 2014

Notes: The table shows the standardized mean differences for the full and matched sample for new houses in the year 2014 . 


\section{A.6 Standardized mean differences: Old houses}

\begin{tabular}{|c|c|c|c|c|c|}
\hline Variable & All & Matched & Variable & All & Matched \\
\hline Semi-detached house & 0.0984 & 0.0000 & Border Rhineland-Palatinate & 0.1420 & 0.0000 \\
\hline 1-family house & -0.1964 & 0.0000 & Border Bavaria & -0.1104 & 0.0000 \\
\hline Unsp. 1- or 2-family house & 0.0070 & 0.0000 & $\log ($ Space $)$ & 0.1211 & -0.0122 \\
\hline Row house & 0.0804 & 0.0000 & $\log ($ Construction year $)$ & 0.0556 & -0.0511 \\
\hline 2-family house & 0.0858 & 0.0000 & $\log ($ No. rooms $)$ & 0.1720 & 0.0035 \\
\hline Garden (Yes) & -0.0335 & -0.0468 & Unemployment & -0.2442 & 0.0553 \\
\hline Good equipment & -0.0149 & -0.0423 & Income tax revenues & 0.5126 & 0.0241 \\
\hline High quality equipment & -0.0486 & 0.0197 & Real estate tax factor & 0.2712 & 0.2390 \\
\hline Normal equipment & 0.0650 & 0.0019 & Refurbishment after 2008 & 0.0057 & 0.0000 \\
\hline Normal building condition & 0.0283 & -0.0033 & Propensity score & 0.7944 & 0.1769 \\
\hline Bad building condition & -0.0229 & 0.0543 & & & \\
\hline Building projected (Yes) & 0.0291 & 0.0000 & & & \\
\hline
\end{tabular}

Table 10: Standardized mean differences for old houses - 2012

Notes: The table shows the standardized mean differences for the full and matched sample for old houses in the year 2012

\begin{tabular}{|c|c|c|c|c|c|}
\hline Variable & All & Matched & Variable & All & Matched \\
\hline Semi-detached house & 0.1055 & 0.0000 & Border Rhineland-Palatinate & 0.1619 & 0.0000 \\
\hline 1-family house & -0.1456 & 0.0000 & Border Bavaria & -0.0914 & 0.0000 \\
\hline Unsp. 1- or 2-family house & -0.0001 & 0.0000 & $\log ($ Space $)$ & 0.0611 & -0.0232 \\
\hline Row house & 0.0690 & 0.0000 & $\log ($ Construction year $)$ & 0.0379 & -0.0663 \\
\hline 2-family house & 0.0268 & 0.0000 & $\log ($ No. rooms $)$ & 0.1311 & 0.0005 \\
\hline Garden (Yes) & -0.0690 & -0.0292 & Unemployment & -0.2094 & 0.0609 \\
\hline Good equipment & 0.0091 & -0.0160 & Income tax revenues & 0.5497 & 0.0463 \\
\hline High quality equipment & -0.0800 & -0.0570 & Real estate tax factor & 0.1178 & 0.1334 \\
\hline Normal equipment & 0.0723 & 0.0463 & Refurbishment after 2008 & -0.0214 & 0.0000 \\
\hline Normal building condition & 0.1211 & -0.0137 & Propensity score & 0.7209 & 0.1010 \\
\hline Bad building condition & -0.0604 & 0.0124 & & & \\
\hline Building projected (Yes) & 0.0011 & 0.0000 & & & \\
\hline
\end{tabular}

Table 11: Standardized mean differences for old houses - 2013

Notes: The table shows the standardized mean differences for the full and matched sample for old houses in the year 2013 . 


\begin{tabular}{|c|c|c|c|c|c|}
\hline Variable & All & Matched & Variable & All & Matched \\
\hline Semi-detached house & 0.1148 & 0.0000 & Border Rhineland-Palatinate & 0.0783 & 0.0000 \\
\hline 1-family house & -0.1881 & 0.0000 & Border Bavaria & -0.0214 & 0.0000 \\
\hline Unsp. 1- or 2-family house & 0.0023 & 0.0000 & $\log ($ Space $)$ & 0.0755 & 0.0215 \\
\hline Row house & 0.1001 & 0.0000 & $\log ($ Construction year $)$ & 0.0464 & -0.0303 \\
\hline 2-family house & 0.0423 & 0.0000 & $\log$ (No. rooms) & 0.1646 & 0.0599 \\
\hline Garden (Yes) & -0.0501 & -0.0820 & Unemployment & -0.1398 & 0.0766 \\
\hline Good equipment & 0.0515 & -0.0095 & Income tax revenues & 0.5047 & 0.2162 \\
\hline High quality equipment & -0.0821 & 0.0010 & Real estate tax factor & 0.0126 & 0.0422 \\
\hline Normal equipment & 0.0414 & -0.0099 & Refurbishment after 2008 & 0.0024 & 0.0000 \\
\hline Normal building condition & 0.1025 & 0.0058 & Propensity score & 0.6404 & 0.2421 \\
\hline Bad building condition & -0.0625 & 0.0152 & & & \\
\hline Building projected (Yes) & 0.0322 & 0.0000 & & & \\
\hline
\end{tabular}

Table 12: Standardized mean differences for old houses - 2014

Notes: The table shows the standardized mean differences for the full and matched sample for old houses in the year 2014

\section{A.7 Robustness check: standard hedonic regression}

The results of estimating the hedonic regression in equation 1 without matching and the two step procedure are found in table $13 .{ }^{5}$ We show only the coefficients for our variables of interest. The remaining coefficients show the expected signs for size of living area, number of rooms, etc. and are available from the authors upon request. Compared to the second panel of our main findings, the results do not provide evidence for a negative impact of the state mandate on prices of affected houses. On the contrary, we find a (weakly) significant positive effect of the state mandate on housing prices in 2012 (at the $10 \%$ level) and 2013. These regressions are based on the full data set without genetic matching, which may give rise to biased estimates. In particular, old houses in BadenWuerttemberg in the full sample are typically located in more prosperous municipalities (higher income tax revenues), have more rooms and have more living space compared to old houses outside of Baden-Wuerttemberg. ${ }^{6}$ All these factors are positively related with house prices and may cast doubt on whether these houses are experiencing similar trends. ${ }^{7}$ In the matched samples, these differences are reduced substantially.

\footnotetext{
${ }^{5}$ Given the different procedures, the dependent variable in table 13 is the price of the respective house, whereas the dependent variable in panel b) in table 4 is the price difference of houses in BadenWuerttemberg to their matched counterparts outside of Baden-Wuerttemberg.

${ }^{6}$ The standardized mean differences for these comparisons can be found in appendix A.6.

${ }^{7}$ Even if we control for these variables in a linear way and including municipality fixed effects, there could be influences that are not captured since the exact formulation of the flexible function in equation 1 is unknown.
} 


\begin{tabular}{lccc}
\hline & $(1)$ & $(2)$ & $(3)$ \\
& 2012 & 2013 & 2014 \\
\hline$B W \times$ x & $0.0238^{*}$ & $0.0347^{* *}$ & -0.0036 \\
& $(0.0142)$ & $(0.0147)$ & $(0.0159)$ \\
$B W \times$ xefurbishment $(>2008)$ & 0.0104 & $0.0550^{* *}$ & 0.0064 \\
& $(0.0247)$ & $(0.0262)$ & $(0.0232)$ \\
\hline Observations & 12,116 & 11,125 & 11,792 \\
Adj. $R^{2}$ & 0.6382 & 0.6523 & 0.6400 \\
\hline \hline Notes: The table shows the results for the interaction variable of "BW" with "OLD" \\
and "Refurbishment $>2008)$ ", respectively, while controlling for a set of individual \\
housing characteristics and municipality fixed effects for the three different years \\
(2012-2014). Each year is estimated in a separate regression and using the full data \\
set for the given year. The standard errors are in parentheses and clustered on \\
municipality level. * $\mathrm{p}<0.10, * * \mathrm{p}<0.05, * * * \mathrm{p}<0.01$.
\end{tabular}

Table 13: Results: Standard hedonic regression 
Download ZEW Discussion Papers from our ftp server:

http://ftp.zew.de/pub/zew-docs/dp/

or see:

https://www.ssrn.com/link/ZEW-Ctr-Euro-Econ-Research.html

https://ideas.repec.org/s/zbw/zewdip.html

$$
\text { / / }
$$

ZEW - Leibniz-Zentrum für Europäische Wirtschaftsforschung GmbH Mannheim

ZEW - Leibniz Centre for European

Economic Research

L 7,1 68161 Mannheim · Germany

Phone +49621 1235-01

info@zew.de.zew.de

Discussion Papers are intended to make results of ZEW research promptly available to other economists in order to encourage discussion and suggestions for revisions. The authors are solely responsible for the contents which do not necessarily represent the opinion of the ZEW. 